\title{
Inhaled chemotherapy in lung cancer: future concept of nanomedicine
}

REVIEW

This article was published in the following Dove Press journal:

International Journal of Nanomedicine

21 March 2012

Number of times this article has been viewed

\section{Paul Zarogoulidis' \\ Ekaterini Chatzaki ${ }^{2}$ \\ Konstantinos Porpodis' \\ Kalliopi Domvri' \\ Wolfgang Hohenforst- \\ Schmidt ${ }^{3}$ \\ Eugene P Goldberg ${ }^{4}$ \\ Nikos Karamanos ${ }^{5}$ \\ Konstantinos Zarogoulidis ${ }^{\prime}$}

'Pulmonary Department,

"G Papanikolaou" General

Hospital, Aristotle University

of Thessaloniki, Greece;

${ }^{2}$ Pharmacology Laboratory, Medical

School, Democritus University of

Thrace, Alexandroupolis, Greece;

III Medical Clinic, Hospital Coburg,

University of Wurzburg, Coburg,

Germany; ${ }^{4}$ Biomaterials Science and

Engineering, Department of Materials

Science and Engineering, University

of Florida, FL; ${ }^{5}$ Biochemistry

Laboratory, Department of Chemistry,

University of Patra, Greece
Correspondence: Paul Zarogoulidis "G Papanikolaou" General Hospital, Aristotle University of Thessaloniki, Greece

Tel +30 697727 I974

$\mathrm{Fax}+302310992433$

Email pzarog@hotmail.com
Abstract: Regional chemotherapy was first used for lung cancer 30 years ago. Since then, new methods of drug delivery and pharmaceuticals have been investigated in vitro, and in animals and humans. An extensive review of drug delivery systems, pharmaceuticals, patient monitoring, methods of enhancing inhaled drug deposition, safety and efficacy, and also additional applications of inhaled chemotherapy and its advantages and disadvantages are presented. Regional chemotherapy to the lung parenchyma for lung cancer is feasible and efficient. Safety depends on the chemotherapy agent delivered to the lungs and is dose-dependent and time-dependent. Further evaluation is needed to provide data regarding early lung cancer stages, and whether regional chemotherapy can be used as neoadjuvant or adjuvant treatment. Finally, inhaled chemotherapy could one day be administered at home with fewer systemic adverse effects.

Keywords: inhaled chemotherapy, carriers, transducers

\section{Introduction}

Lung cancer is responsible for $23 \%$ of total cancer deaths. ${ }^{1}$ Cancer survival tends to be poorer due to an often advanced stage at diagnosis. Only a minority of patients are eligible for curative surgical treatment. Until now, although new biomarkers have been under development for early diagnosis of lung cancer, early detection of lung cancer has not been achieved. Nonsmall cell lung cancer is the most common type of lung cancer worldwide, and various clinical studies are currently assessing new chemotherapeutic combinations. ${ }^{2-4}$ Although targeted and tailored therapies have been introduced for patients according to individual biological tumor characteristics, overall survival rates have failed to demonstrate the expected progression-free survival or overall survival. ${ }^{5,6}$ Moreover, acquired resistance to cytotoxic agents has been observed, mainly involving the apoptotic mechanism in nonsmall cell lung cancer cell lines. ${ }^{7}$ In small cell lung cancer, five-year survival remains less than $10 \%$, despite use of various drug combinations. ${ }^{8,9}$ In addition, acquired resistance has been observed in small cell lung cancer. ${ }^{10}$ Therefore, novel therapies are in great demand. The drug concentration reached in solid tumors is a key parameter for successful treatment and, until now, drug concentration at the tumor site has been found to be low after systemic chemotherapy. ${ }^{11,12}$

Nevertheless, drugs already being used for systemic administration have been successfully administered regionally in various types of cancer. ${ }^{13-23}$ The concept of local drug delivery is proposed as a method for delivering high drug concentrations to the target site while preventing exposure of vital organs to toxic drug concentrations in the systemic circulation. In this way, systemic side effects are minimized. The respiratory 
system has a large surface area, thin alveolar epithelium, rapid absorption, lack of first-pass metabolism, high bioavailability, and the capacity to absorb large quantities of drug, making it an optimal route of drug administration. ${ }^{24}$ Aerosol therapy has also been evaluated, and is being used for several other conditions and purposes, such as diabetes mellitus, gene therapy, and vaccination. ${ }^{25-29}$ Regarding aerosol chemotherapy administered for lung cancer, a number of drugs have been investigated in vitro, in animal models, and in human trials. ${ }^{30-64}$ Several aspects of this treatment modality have been addressed due to the necessity for trials to be conducted, but several parameters remain to be clarified and expanded. The areas of this treatment modality that need to be properly addressed are summarized under the headings: prompt inhalation device; lung airway microenvironment; appropriate molecule-chemotherapy selection; deposition evaluation; protection measures; and disease evaluation. In the current review, these topics will be addressed based on the published literature, and all prior knowledge on the subject will be presented.

We performed an electronic search of the PubMed, Google Scholar, Medscape, and Scopus databases using combinations of the following keywords: "aerolized chemotherapy", "inhaled chemotherapy in lung cancer", "nanoparticles", "aerosol devices", “encapsulation”, "inhaled doxorubicin”, "inhaled carboplatin", "inhaled cisplatin", "inhaled paclitaxel", "inhaled docetaxel", and "inhaled 5-fluororacil". All types of articles (randomized controlled trials, clinical trials, observational cohort studies, review articles, case reports) were included. Selected references from identified articles were searched for further relevant papers.

\section{Lung anatomy and microenvironment}

\section{Airway geometry and humidity}

Human lungs have a large $\left(>100 \mathrm{~m}^{2}\right)$, thin $(0.1-0.2 \mu \mathrm{m})$, and highly vascular epithelial surface area for absorption. Progressive branching and narrowing of the airways encourages impaction of particles. The lung has a relative humidity of approximately $99.5 \%$. Drug particles are known to be hygroscopic and to grow or shrink in size in high humidity. The increase in particle size above the initial size should affect the amount of drug deposited and, particularly, distribution of the aerosolized drug within the lung. ${ }^{65,66}$ Further drug absorption could occur via the lymphatic pathway. ${ }^{67,68}$

\section{Bronchial circulation}

The lungs receive the entire cardiac output and represent the most richly perfused organ in the body. However, only the alveolar region is supplied by the pulmonary circulation. Blood flow to the larger airways (trachea, bronchi) is via the systemic circulation, and these airways receive approximately $1 \%$ of cardiac output. ${ }^{69}$ The endobronchial circulation is recirculated to the peripheral airways and lung parenchyma via the bronchial veins and right atrium. Bronchial blood flow is augmented in diseases such as bronchiectasis, from $1 \%$ to as much as $30 \%$ of cardiac output. ${ }^{24}$ Theoretically, inhaled drugs that are absorbed into the circulation from the tracheobronchial regions can be redistributed downstream and peripherally into otherwise poorly accessible areas of the lung, which may aid in drug effectiveness. ${ }^{70}$

\section{Lung clearance mechanisms}

Drug particles deposited in the conducting airways are largely removed by mucociliary clearance. The airway epithelial goblet cells and submucosal glands secrete mucus, forming a two-layer mucus blanket over the ciliated epithelium, ie, a low-viscosity sol layer covered by a high-viscosity gel layer. Insoluble particles are trapped in the gel layer and are moved toward the pharynx (and ultimately to the gastrointestinal tract) by the upward movement of mucus generated via metachronous beating of the cilia.

In the normal lung, the rate of mucus activity varies depending on the airway area and is determined by the number of ciliated cells and their beat frequency. For normal mucociliary clearance to occur, the airway epithelial cells and ciliary structure and activity must remain intact. Further, the depth and chemical composition of the sol layer should be optimal and, finally, the rheology of the mucus must also remain within the physiological range. Mucociliary clearance is impaired in lung diseases such as immotile cilia syndrome, bronchiectasis, cystic fibrosis, and asthma. ${ }^{71}$ Lipophilic molecules pass easily through the airway epithelium via passive transport. Hydrophilic molecules cross via extracellular pathways and exocytosis. ${ }^{72}$ Particles are absorbed from the submucosal region into the systemic circulation, bronchial circulation, or lymphatic system. Drugs deposited in the alveolar region may be phagocytosed and cleared by alveolar macrophages or absorbed into the pulmonary circulation. Alveolar macrophages are the predominant phagocytic cells for lung defense against inhaled microorganisms, particles, and other toxic agents. There are approximately five to seven alveolar macrophages per alveolus in the lungs of healthy nonsmokers. ${ }^{73}$ Macrophages phagocytose insoluble particles that are deposited in the alveolar region and are either cleared by the lymphatic system or moved into the ciliated airways along currents in alveolar fluid and then cleared via 
the mucociliary escalator. ${ }^{74}$ This process can take weeks to months to complete. ${ }^{75}$ Moreover, enzymes are still present in the lungs, so particles can be enzymatically degraded intracellularly (from alveolar macrophages) and/or extracellularly by membrane-associated proteases and peptidases (both epithelial and endothelial). ${ }^{76}$

\section{Lung disease}

Bronchoconstriction, inflammation, and airway narrowing alter lung deposition. Respiratory diseases, such as cystic fibrosis and bronchiectasis, change the architecture of the lung. Alterations in bifurcation angles, turbulent flow, and obstruction of the airways due to mucus accumulation modify the deposition and distribution patterns of aerosols. A decrease in the cross-sectional area of the lung caused by obstruction increases air velocities and turbulence in regions where the airflow is usually laminar. Airway obstruction diverts inspired air to unobstructed airways and, thus, remarkably little drug is deposited in obstructed areas. Often the obstructed areas are those that need to be reached in order to achieve the optimal therapeutic effect of a drug. ${ }^{71,77-80}$ Inhaled insulin was investigated as to whether it could be administered during an exacerbation and how this situation altered the dosage. It was observed that the drug could be administered and was tolerated by patients, but close glucose monitoring was required because release of the drug into the systemic circulation was insufficiently controlled. ${ }^{29}$

\section{Methods enhancing lung deposition}

It has been confirmed by plethysmography that addition of $5 \%-7 \% \mathrm{CO}_{2}$ into the inhalation system enhances the depth of absorption and drug quantity inhaled in every breath by reducing the respiratory rate and increasing the tidal volume by $180 \%$. The subject is forced to breathe slowly and deeply. Nevertheless, it has been observed that if the mixture is enriched with a concentration higher than $7 \%$, adverse effects are observed, with sleepiness, confusion, and severe dizziness being the most common. ${ }^{81-83}$

\section{Tumor size}

Tumor size affects the distribution and deposition of the inhaled compound. In previously published studies, the mass median diameter was required to be $\leq 3-5 \mathrm{~cm}$ upon diagnosis, otherwise patients were excluded from trials. $^{29,40,52,53,84,85}$ Anticancer drugs penetrate normal tissues by both diffusion and convection, ${ }^{86}$ with the net flow of fluid from blood vessels balanced by resorption into the lymphatic circulation. Nevertheless, tumors caused by unstructured neoangiogenesis lack functional lymphatics, ${ }^{87,88}$ which can lead to increased levels of interstitial fluid pressure in tumors, ${ }^{89-91}$ which in turn reduces convection and inhibits distribution of macromolecules. ${ }^{92,93}$ It has been previously demonstrated that some physicochemical properties of drugs, ie, shape, charge, molecular weight, and aqueous solubility, determine the rate of diffusion through tissue. ${ }^{86}$ The penetration of a drug is also dependent on its deconstruction, which functions to remove free drug, thereby inhibiting further permeation. ${ }^{86}$ Water-soluble drugs distribute most readily in the extracellular matrix and thus diffuse efficiently around and between cells. In contrast, lipid-soluble drugs penetrate lipid membranes, and so can be transported through cells.

\section{Physical properties of drug formulations}

Physical properties that have a significant role on the particle size of the inhaled suspension are viscosity ionic strength, osmolarity, and $\mathrm{pH}$. If the values for $\mathrm{pH}$ and osmolarity in particular are not in the normal range, bronchoconstriction, coughing, and irritation of the lung mucosa is induced. ${ }^{94,95}$

\section{Drug delivery systems Optimal particle size}

The inhaled drug formulation should consist of a specific particle size, in the range of $1-3 \mu \mathrm{m}$, to achieve substantial alveolar deposition. ${ }^{24}$ Inhaled molecules of this size becomes trapped in the alveoli and taken up in vesicles by alveolar epithelial cells, so that they can be carried across and released on the opposite side in the narrow interstitial fluid compartment between the epithelial cells. Molecules are then taken up within vesicles by the endothelial cells, transported across the width of these cells, and released into the alveolar capillary bloodstream. This process of particle migration into, across, and out of a cell is known as transcytosis. Other drug formulations given via inhalation, such as corticosteroids and anticholinergics, do not have to be less than 2-3 $\mu \mathrm{m}$ in size, because they act on the larger branches of the bronchial tubes. ${ }^{96}$

\section{Pressurized metered dose inhalers}

The pressurized metered dose inhalers (MDIs) use propellants, such as chlorofluorocarbons, which have been recently replaced by hydrofluoroalkanes. ${ }^{97}$ The aerosol is emitted through a nozzle at a high velocity of $>30 \mathrm{msec}$ ). Nevertheless, only $10 \%-20 \%$ of the aerosol emitted from pressurized MDIs is deposited on the lung parenchyma. ${ }^{98}$ The main reasons for this can be summarized as inspiratory flow rate and lack of hand-mouth coordination, ${ }^{99-101}$ and 
the impact of high velocity particles and large particle size $(50 \%-80 \%)$ on the oropharynx. ${ }^{102}$ In order to maximize the effectiveness of drug absorption from a pressurized MDI, the patient has to breathe slowly by decreasing respiratory frequency and increasing tidal volume. The inhaled volume is increased and the aerosol penetrates deeply into the lung parenchyma. ${ }^{103,104}$ To overcome the problem of actuationinhalation, coordination breath-actuated pressurized MDIs were introduced to the market. ${ }^{105}$ Nevertheless, improved peripheral deposition was observed if patients did not hold their breath on completion of inhalation in comparison with pressurized MDIs that are not breath-actuated. ${ }^{106}$ In addition, different spacer tubes, valved holding chambers, and mouth piece extensions were developed to reduce deposition in the oropharynx by decreasing particle size and slowing the velocity of the aerosol, and to produce a finer aerosol of smaller mass median aerodynamic diameter. ${ }^{107}$

\section{Dry powder inhalers}

Dry powder inhalers were designed to overcome poor actuation-inhalation coordination. There are two basic types on the market, ie, multidose (containing multiple doses) and single-dose capsule dry powder inhalers. Several differences in lung deposition have been observed between the various dry powder inhalers. Approximately $12 \%-40 \%$ of the emitted dose is delivered to the lungs, and about $20 \%-25 \%$ is retained within the device. ${ }^{108-110}$ The reduced drug deposition has been attributed to inefficient disaggregation of ultrafine drug particles from coarser carrier lactose particles or drug pellets. Factors affecting disaggregation are high humidity, slow inhalation flow rate, and rapid and large deviations in temperature. ${ }^{111}$ Therefore, dry powder inhalers have to be stored in a cool, dry place. In addition, an exhalation maneuver is required before inhalation, because there is the possibility for a patient to exhale into the inhaler nozzle and disperse the dry powder. Pulmonary drug administration is enhanced for the dry powder inhalers because of fast inhalation. ${ }^{112}$ This occurs due to different internal resistance to airflow and a range differentiation from low to high resistance. ${ }^{113,114}$ Failure to use the device properly is a common error and therefore a dose is not delivered promptly. ${ }^{115}$ Dry powder inhalers with high resistance provide increased deposition to the lung parenchyma, ${ }^{113,116}$ but the clinical significance of this remains to be clarified. Finally, recent developments, principally in overcoming forced inhalation effort, have produced active dry powder inhalers. This is achieved either by adding a battery-driven propeller that aids the dispersion of the powder or by using compressed air to aerosolize the powder and convert it to an aerosol in a holding chamber where its respiration is independent of the respiratory capability of the patient. Dry powder inhalers that are currently on the market are breath-actuated and still depend on the inhalation flow rate of the patient to achieve maximum drug dose inhalation. ${ }^{117}$

\section{Nebulizers}

Nebulizers have been used for many years to treat various respiratory diseases. They work by inhalation through a face mask, and can be used in respiratory distress by the elderly and children younger than 2 years of age. In addition, they can deliver large quantities of solutions and suspensions as small droplets with remarkably little patient coordination required. There are certain parameters of the aerolized solution affecting their efficiency, ie, $\mathrm{pH}$, viscosity, ionic strength, osmolarity, and surface tension. High drug concentration, extremely low $\mathrm{pH}$, and hyperosmolarity or hypo-osmolarity reduce drug output and provoke bronchoconstriction, coughing, and irritation. ${ }^{94,95}$ Other additional significant factors can be summarized as the design of the nebulizer chamber, primary drug fill in the reservoir cup, tapping of the nebulizer chamber during nebulization, time taken to nebulize a solution, gas flow and compressor characteristics, and residual volume. ${ }^{118}$ Until recently, there were two basic types of nebulizers, ie, jet nebulizers and ultrasonic nebulizers. Jet nebulizers take advantage of the energy provided by compressed gas flow and distribute the liquid substance in the reservoir cup into a fine mist. Jet nebulizers are widely used, but are rather inadequate $(50 \%$ loss when continuously operated and only $10 \%$ deposited to the lungs) in comparison with the newer devices described below. ${ }^{119}$ Their performance is largely dependent on the compressor used. ${ }^{118,120}$ Newly introduced to the market are the breath-enhanced jet nebulizers and the dosimetric nebulizers. The former delivers drug faster than the conventional jet nebulizers and the latter are breath-actuated, so generate aerosol only by inhalation. They are computer-controlled, and although they contribute by saving aerosol (up to $60 \%$ ), they remain extremely expensive in comparison with conventional jet nebulizers. ${ }^{121}$ The ultrasonic nebulizers use a piezoelectric crystal that vibrates at a high frequency $(1-3 \mathrm{mHz})$ to produce a mist of liquid in the nebulizer. The higher the frequency used, the smaller the droplets produced. Ultrasonic nebulizers nebulize solutions faster than jet nebulizers, but are not suitable for suspensions. In addition, the piezoelectric crystal can heat and inactivate protein-based drugs. ${ }^{122}$ The latest nebulizers introduced onto the market are the vibrating mesh nebulizers, 
which are divided either into active or passive systems. Their advantages over the previous systems are that they are very efficient, quiet, and portable, and have an extremely low residual volume to prevent drug waste. Moreover, some models provide feedback to the patient regarding dose delivery and patient adherence. Nevertheless, there are a number of disadvantages, in that they are expensive, and need maintenance and cleaning to prevent colonization by pathogens, buildup of deposits, and blockage of the apertures. Finally, although vibrating mesh nebulizers are highly efficient overall, their performance varies according to the drug solution used and, therefore, licensing specific drugs with specific nebulizers is essential. This has no significant clinical importance when bronchodilators are delivered, given that they have a wide therapeutic index, but it is necessary when delivering drug solutions containing liposomes or proteins. ${ }^{123-126}$ Facemasks are used for patients with acute respiratory distress and in uncooperative individuals. The facemask is not just a feature connecting the nebulizer to the patient, it also has to prevent face and ocular irritation. ${ }^{127-130}$ A mouthpiece is also used, and new mouthpiece designs are currently on the market which enable inhalation by breath actuation, incorporate drug-saving technology, and are environment friendly, protecting medical staff from having to dispose of unwanted solutions..$^{29,30}$ Nevertheless, the mouthpiece is not indicated for acute respiratory distress conditions. Kleinstreuer et $\mathrm{a}^{84,131}$ have presented data regarding the optimal combination of particle size, particle release position, and inhalation waveform that may deliver inhaled drug aerosols efficiently to the desired areas. Micron-sized particles follow trackable trajectories in human lung airways under steady laminar flow conditions. Therefore, the mouth inlet plays a crucial role, because it can affect the dispersion and deposition of the aerosol by backtracking.

\section{Soft mist inhalers}

Currently there is only one drug system of this kind available, which is a mechanical achievement of outstanding value. It uses the energy of a spring to force the solution through an extremely fine nozzle system. ${ }^{132,133}$ It produces a fine aerosol with relatively high lung deposition. ${ }^{134-136}$

\section{Inhaled particle carriers and strategies Liposomes}

Liposomes have a variety of properties that can be summarized as sustained release with reduced toxicity and less irritation to the lung parenchyma, the possibility to manipulate release and targeting, and improved stability. ${ }^{137}$ The amount of drug dose carried by the liposomes, and their release rate and deposition in the lung parenchyma depends on lipid composition, size, charge, drug/lipid ratio, and method of delivery. ${ }^{138-140}$ Liposomes are produced from phospholipids, which carry either no charge or a net negative/ positive charge. ${ }^{111,141}$ Their structure consists of an aqueous volume entrapped by a synthetic lipid single layer or bilayer with or without cholesterol. They are capable of encapsulating either hydrophilic or lipophilic formulations. ${ }^{122,143}$ However, formulations of intermediate solubility are poorly retained by liposomes, so they are manipulated to achieve a higher degree of retention. ${ }^{144}$ Liposomes are prepared for inhalation either in liquid or dry powder form. ${ }^{145}$ During nebulization, an amount of the formulation is lost and hence a manipulation of the lipid composition, and size and operating conditions are necessary to minimize the loss. ${ }^{146-149}$ The dry powder liposome formulations are produced by lyophilization followed by milling or by spray-drying. ${ }^{150,151}$ The sustainedrelease capability of liposomes has been observed in several studies using a variety of drugs as aerosol treatment for the lung. ${ }^{29,50,152}$ To enhance the sustained-release properties of liposomes further, a polymer surface coating, such as polyethylene glycol (PEG), was developed. This addition, provided a "stealth" shield to the molecule to bypass the body's defense mechanisms ${ }^{144,153,154}$ (Table 1).

\section{Microparticles}

Microparticles are produced from naturally occurring or synthetic polymers, and their size range is between 0.1 and $500 \mu \mathrm{m}$. They are physically and chemically more stable than liposomes, so are capable of higher drug loading. This property makes them an ideal carrier system for proteins and peptides. ${ }^{155,156}$ In order to encapsulate a drug, a number of factors, including heat, $\mathrm{pH}$, oxygen, solvents, moisture, and mechanical stresses, must be assessed. Preparation for aerosol delivery can be undertaken using spray-drying, emulsion-solvent evaporation, phase separation, emulsion-solvent diffusion, and supercritical fluid technology. ${ }^{157-163}$ Moreover, manipulation of the following parameters will determine drug release: concentration, size, solubility, nature of micromolecular drug, molecular weight, porosity, tortuosity, and uniformity of the polymer. A coating is added to improve the time release characteristics further, and 1,2-dipalmitoylphosphatidylcholine is also added to poly(DL-lactide-co-glycolide) microspheres to decrease uptake by macrophages. ${ }^{160}$ When chitosan and hydroxypropylcellulose are added to the particles, their 
Table I Efficiency enhancement mechanisms

\begin{tabular}{l} 
Liposome composition (neutral or anionic lipids) \\
Phosphatidylcholines (lecithins) \\
Phosphatidylethanolamines Sphingomyelins \\
Phosphatidylserines \\
Phosphatidylglycerols \\
Phosphatidylinositols \\
Microparticles \\
Polylactic acid \\
Polylactic-co-glycolic acid \\
Sodium hyaluronate \\
Calcium phosphate-polyethylene glycol particles \\
Oligosaccharide derivatives \\
Oligosaccharide-lipid mix \\
Lipid-based Pulmosphere \\
Carbohydrates \\
Xylitol \\
Maltitol \\
Glucose \\
Sorbitol \\
Mannitol \\
Lactose \\
Cyclodextrins \\
Pegylation \\
Biodegradable polymers \\
Polylactic acid \\
Oligolactic acid \\
Mucoadhesive polymer \\
Bioadhesives \\
Lectins \\
Peptides \\
Antibodies \\
Heparin \\
Heparin sulfate \\
Octa-arginine \\
Antibodies \\
Cell-type specific targeting \\
Alveolar macrophages \\
Cancer cells \\
Epidermal growth factor \\
Low-density lipoprotein \\
Intaricalization \\
\hline
\end{tabular}

time residence in the lung parenchyma is increased. ${ }^{163}$ It has been widely agreed that the optimal geometric diameter for lung delivery is $1-3 \mu \mathrm{m}$, but these particles tend to aggregate ${ }^{164}$ and are cleared by alveolar macrophages. ${ }^{165}$ Therefore, large porous particles were developed with a geometric diameter of $>5 \mu \mathrm{m}$, an aerodiameter of $<5 \mu \mathrm{m}$, and a low density of $<0.1 \mathrm{mg} / \mathrm{mL} .{ }^{166}$ When aerolized, large porous particles deposit homogeneously on the cell surface and, when observed by microscopy, appear nontoxic. ${ }^{161}$ Further development of this molecule has led to "Trojan" particles, ${ }^{165}$ which have the ability to escape both phagocytic and mucociliary clearance in the respiratory system. They are prepared from nanoparticles, which eventually assemble into a microparticle of low density $(<0.1 \mathrm{mg} / \mathrm{mL})$. These particles need to be assessed with a drug load, but published data suggest that they can be aerosolized from dry powder. ${ }^{157}$ It has been shown previously that a single cancer cell can ingest one or multiple microparticles. The ingested microparticles are arranged in such a way as to reduce the space occupied inside the cell, and the same occurs with macrophages $^{44,167}$ (Table 1, Figure 1).

\section{Carbohydrates}

There are currently three carbohydrate formulations approved by the US Food and Drug Administration, ie, lactose (a-lactose monohydrate), glucose, and mannitol (polyol). These carriers contribute to drug flow and dispersability, and also act as stability enhancers. In a recent study, several carriers such as mannitol, sorbitol, maltitol, and xylitol, were assessed and it was concluded that mannitol is the best candidate for dry powder inhaler formulation, given that the others showed limited dispersability. ${ }^{168}$ Techniques used to produce a respirable formulation are: supercritical fluid technology, spray-freeze drying, freeze-drying, and lyophilizing followed by milling/jet milling or spray-drying. ${ }^{169-173}$ Moreover, it has been observed that lactose enhances the uptake of polylysine into airway cells, and this has been shown to be a method of increasing intracellular localization of proteins and peptides. ${ }^{174}$ Two approaches have been developed to improve delivery efficiency and increase drug dispersibility and the respirable fraction. The first approach was mixing fine lactose particles (about $5 \mu \mathrm{m}$ in diameter) with coarse lactose to improve disaggregation, as well as the fine particle fraction. ${ }^{175}$ The second approach was to add a ternary component, such as L-leucine,

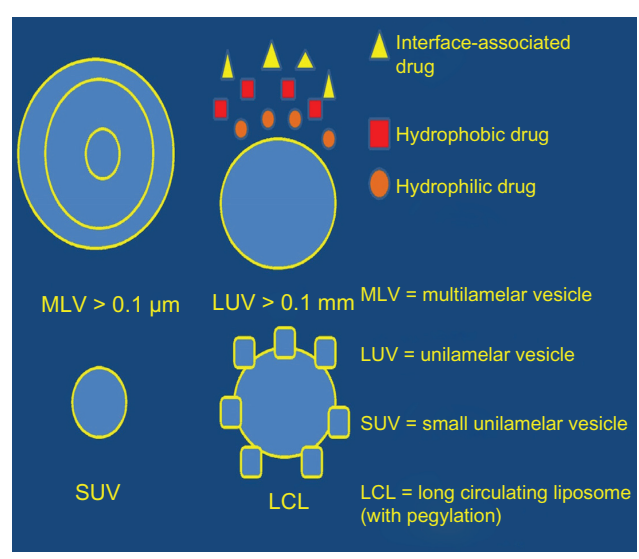

Figure I Encapsulation vehicles. 
to the formulation. ${ }^{111}$ Finally, cyclodextrins, which are cyclic oligosaccharides, have proven to be useful excipients in the respiratory distribution of small molecules. ${ }^{176}$ Until recently, their use for protein/peptide delivery was limited due to the need to address penetration enhancement. However, in a recent study, the use of dimethyl- $\beta$-cyclodextrin presented increased bioavailability, with increasing concentrations of cyclodextrin $^{169}$ (Table 1).

\section{Pegylation}

PEG added to proteins enables sustained release on the site of deposition. This is achieved by bypassing the defense mechanisms of the respiratory tract, by decreasing degradation of the formulation, and prolonging the half-life in the lungs. ${ }^{144,154,177}$ In addition, PEG has been demonstrated to be a safe carrier for inhalational agents ${ }^{178}$ (Table 1).

\section{Biodegradable polymers}

Polylactic acid has sustained release properties, but is not suitable for pulmonary drug delivery due to its prolonged biological half-life. An oligomer of lactic acid, with a shorter half-life (6-8 days), can be used for drug delivery. The mucoadhesive polymer, hydroxypropyl cellulose, is released over approximately 24 hours and bypasses mucociliary clearance. However, the toxicity profile of hydroxypropyl cellulose has not been established ${ }^{111,179}$ (Table 1).

\section{Bioadhesives}

Bioadhesives are used to prolong the connection between the carrier-drug and the surface cell in the airway. ${ }^{180,181}$ A number of multivalent binding agents have been incorporated in drug-carrier systems, including lectins, peptides, antibodies, octa-arginine, heparin, heparin sulfate, and antibodies ${ }^{182,183}$ (Table 1).

\section{Cell targeting}

Cell targeting has been the focus of increasing interest in recent years, both from the prognostic and therapeutic points of view. Gene therapy has been widely investigated in cell-selective targeting. ${ }^{184}$ Alveolar macrophages are an attractive vehicle by which to deliver a chemotherapeutic agent to the lymph nodes through the lymphatic circulation. Liposomes and microspheres are generally engulfed by alveolar macrophages. Several receptors are overexpressed, such as epidermal growth factor and folic acid, which can be exploited to target specific cells in cancer therapy. ${ }^{185,186}$ Low-density lipoprotein has been used for receptor assimilation $^{187}$ (Table 1).

\section{Intracellular targeting}

Intracellular targeting is an additional strategy to improve the efficiency of a drug. The general concept is to create a potent drug that would reach the proper surface area, but intracellular targeting is essential to take regional therapy a step further. ${ }^{188,189}$ In this regard, most chemotherapy regimens interact within the reproductive cell cycle, so this targeting strategy could be further pursued. ${ }^{190}$ There are three parameters that are investigated concerning the cell microenvironment and drug-formulation interactions, ie, intracellular trafficking, endosomal release, and nuclear localization (Table 1).

\section{Drug transporters}

\section{ATP-binding cassette transporters}

ABC transporters are a large family (50 members) of transmembrane proteins, which act as an ATP-dependent efflux system exporting molecules from the cytoplasm to the surrounding cellular environment. There are seven subfamilies, from A to G. ABC transporters prevent accumulation of xenobiotics, so they serve as a defense mechanism in lung tissue. ${ }^{191}$ P-glycoprotein, multidrugresistant proteins, and the breast cancer resistance protein are known to play a role in multidrug resistance, a characteristic observed during the expulsion of chemotherapeutic agents from cancer cells. ${ }^{192}$ P-glycoprotein has been extensively studied in the lung. It decreases oral drug absorption, prevents drug entry in the central nervous system, and is responsible for many drug-drug interactions. ${ }^{193}$ The transporter is localized based on immunohistochemistry techniques on the apical membrane of the bronchial and bronchiolar epithelium, ${ }^{194-197}$ in the endothelial cells of the bronchial capillaries, ${ }^{198}$ and in alveolar macrophages. ${ }^{195,196}$ Expression of P-glycoprotein in smokers with lung disease versus people with normal lungs has not been adequately investigated. P-glycoprotein and immunohistochemical multidrug-resistant protein analyses are a useful tool for predicting a patient's response to chemotherapy. ${ }^{199}$ In one study, mRNA levels in the lung tissue of smokers, nonsmokers, and exsmokers were not found to be significantly different. ${ }^{194}$ Several studies have demonstrated directly or indirectly that underlying disease plays a role in regulation of the P-glycoprotein transporter. In addition, pharmaceuticals administered for lung or other disease can upregulate the P-glycoprotein transporter. In cystic fibrosis, due to changes induced by the disease, it has been observed that the P-glycoprotein transporter is upregulated. ${ }^{200,201}$ Moreover, it has been reported that toxins released from microorganisms infecting patients with cystic fibrosis also 
inhibit P-glycoprotein. ${ }^{202}$ In patients with chronic obstructive pulmonary disease (COPD), there are no significant data indicating modification of P-glycoprotein between the disease stages, ${ }^{203,204}$ and no relevant data exist for asthma patients. Corticosteroids administered by the inhaled, oral, and intraperitoneal routes upregulate the P-glycoprotein transporter. ${ }^{205-207}$ A particularly good example of the importance of transporters in inhaled chemotherapy is the inhibition of P-glycoprotein by lipid nanocapsules, which is a crucial mechanism of resistance for paclitaxel. ${ }^{208}$ There are nine multidrug proteins (MRPs). In normal lung tissue, MRP 1 and MRP 5 have been found to be highly expressed. MRP 6 and MRP 7 are moderately expressed, and MRPs 2, 3, 4, 8, and 9 are either low or undetectable. ${ }^{209,210}$ MRP 1 and MRP 2 are found in the bronchial and bronchiolar epithelium. ${ }^{195,211,212}$ MRP 1 is also found in alveolar macrophages. ${ }^{195,211}$ MRP 1 expression and levels are altered in patients with COPD. ${ }^{203,211}$ It has been previously shown that smoking downregulates the transporter, and the transporter has a protective role against cell damage. ${ }^{203,213}$ Ipratropium, $\mathrm{N}$-acetylcysteine, and budesonide stimulate MRP 1 efflux and activity. ${ }^{214}$ Formoterol in combination with budesonide reduces transporter activity, but formoterol on its own does not have an effect on the transporter. ${ }^{214}$ In a study of inhaled doxorubicin, MRP 1 and MRP 2 were overexpressed. ${ }^{51}$ This information is crucial, because most lung cancer patients are also diagnosed with COPD. Breast cancer resistance proteins were first isolated from breast cancer cell lines. In a recent study, they were found to be highly expressed in human lung tissue using gene microarrays ${ }^{215}$ (Figure 2).

\section{Organic cation transporters}

Organic cation transporters belong to the greatest facilitator family and comprise five types of carriers, ie, electrogenic OCT 1, OCT 2, and OCT 3, and electroneutral OCTN 1 and OCTN 2. OCT 1-3 are found in the trachea, smooth muscles of the airway, and ciliated bronchial cells, but there are contradictory data in terms of their expression. OCT $\mathrm{N} 1$ is expressed in the tracheal epithelium and alveolar macrophages, whereas OCT N2 is expressed in the alveolar epithelium and airway epithelium. ${ }^{215-218}$ Published data for animal and in vitro cell lines implicate upregulation or downregulation of OCT transporters upon induced inflammation or drug interactions related to asthma and/or COPD. Nevertheless, these are not clearly associated with a human model $^{217-220}$ (Figure 2).

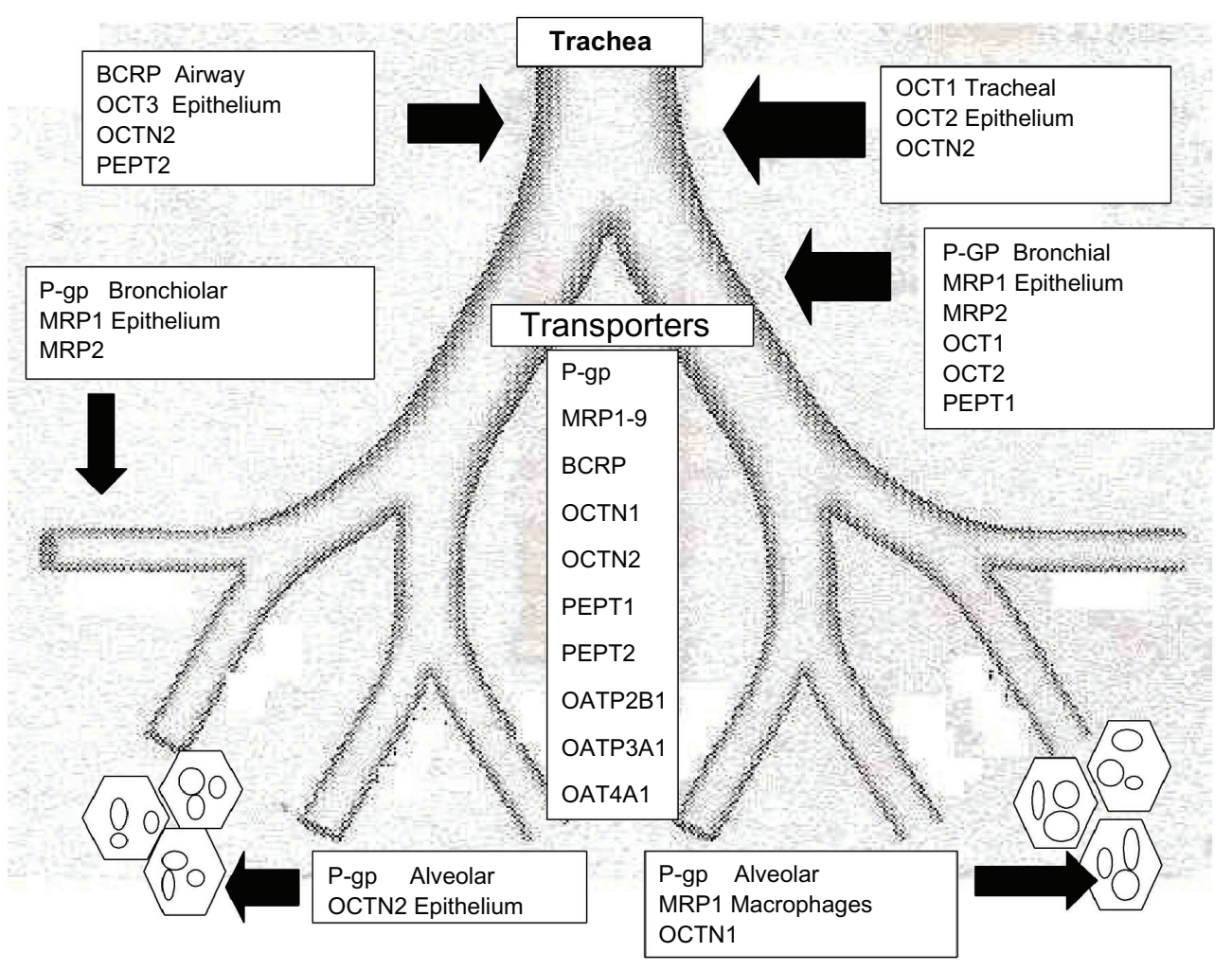

Figure 2 Transporters and their position where they are most highly expressed.

Abbreviations: P-gp, P-glycoprotein; BCRP, breast cancer resistance protein; MRP, multidrug resistance-associated proteins; PEPT, peptide transporters; OCT, organic cation transporters; OCTN, organic cation transporters electroneutral; OAT, organic anion transporters; OATP, organic anion transporting proteins. 


\section{Peptide transporters}

Peptide transporters are part of the proton-coupled oligopeptide transporter group. The two main transporters are PEPT 1 and PEPT 2, which contribute to the high bioavailability of peptide-like molecules. These peptides can affect the absorption and distribution of several inhaled antibiotic and antiviral drugs. ${ }^{221}$ PEPT 2 and more recently PEPT 1 were detected first in the airway epithelium and then in the bronchial epithelium. ${ }^{222,223}$ These two transporters have also been found in animals and cell lines. ${ }^{224,225}$ However, how they interact with drug formulations and their activity in respiratory diseases ${ }^{226}$ has not been fully investigated.

\section{Organic anion transporters}

There are six members identified, ie, OAT 1-4, URAT 1 , and OAT 5, which are mostly found in the kidneys. ${ }^{227}$ Gene microarrays have confirmed their absence in human and murine lungs, but OAT 2 was highly expressed at these sites. ${ }^{215}$ In addition, OAT 4 mRNA was highly expressed in the bronchial cell lines Calu-3 and 16HBE14o-..224

\section{Organic anion transporting polypeptides}

There are 11 human organic anion transporting polypeptides (OATPs), which are divided into six families. ${ }^{228}$ Their actual tissue distribution has not been fully investigated. ${ }^{228}$ OATP 2B1, OATP 3A1, OATP 4C1, and OATP 4A1 expression has been found in human lungs, animals, and cell lines. ${ }^{215,224,229}$

\section{Inhalation studies}

There is a large amount of published data regarding aerosol delivery of chemotherapy in cancer cell cultures, animal models, and Phase I/II human studies (Table 2). These studies are best commented on in terms of the chemotherapeutic agent delivered to the lung parenchyma with additional individual parameters. The first chemotherapeutic agent, investigated almost 30 years ago, was 5 -fluorouracil (5-FU). ${ }^{31}$ Tatsumura et $\mathrm{l}^{32}$ presented data for patients treated with inhaled 5-FU and underwent surgery immediately afterwards, who had higher drug concentrations in the tumor than in the surrounding tissues. In addition, high 5-FU concentrations were found for up to 4 hours after administration in the main bronchus and in the lymph nodes around the main bronchus. ${ }^{32}$ This observation was confirmed in another study using 5 -FU. ${ }^{60}$ Moreover, additional formulations of 5-FU with lipid-coated nanoparticles or difluoromethylornithine, an important enzyme in cell proliferation, were devised to achieve sustained drug release and enhance anticancer properties.$^{60,230,231}$ In these studies, previously presented for their inhalable system carriers with 5-FU, a step was made forward in using inhaled chemotherapy as an adjuvant treatment. Studies using taxanes either with liposome carriers, nanoparticles, polymeric micelles, or lipid nanocapsules provided evidence of an increased therapeutic index by prolonging regional action in the lung. Further, $5 \%-7 \% \mathrm{CO}_{2}$ has been used to enhance aerosolized drug deposition. ${ }^{50,82}$ However, the data are controversial regarding the safety of taxanes at the lung parenchyma. The data indicate that the mononuclear phagocyte system attacks the colloidal drug, so a combination of pegylated lipid nanocapsules is needed to prolong regional action. In addition, further studies will establish their efficacy in human subjects, after proper alterations/ additions to the drug formulation, such as nanoparticle ${ }^{232}$ or nanospheres, ${ }^{233}$ and when linked to human albumin. ${ }^{45,50,59,234,235}$ Moreover, adverse effects, mainly neurotoxicity, was found to be dose-dependent, but also associated with increased tumor burden regression,,$^{50}$ and addition of cyclosporine $\mathrm{A}$ to the paclitaxel aerosol was found to enhance the anticancer effect of the treatment. ${ }^{55}$ It was observed that addition of cyclosporine A reversed the resistance of cancer cells to paclitaxel. ${ }^{55}$ When a taxane compound was compared with doxorubicin, it was noticed that adverse effects on the lung parenchyma were observed for the doxorubicin group, indicating that taxanes are safer in comparison with doxorubicin regarding the lung region. ${ }^{34}$ In addition, severe cardiotoxicity was seen in the doxorubicin group..$^{34,47}$ Otterson et a $\mathrm{l}^{37,52}$ created a protocol for inhaled chemotherapy in human subjects, covering all aspects of this treatment modality. Two Phase I and Phase I/II studies demonstrated the adverse effects of aerosol treatment, such as a metallic taste, mild bronchospasm, and moderate reduction of pulmonary function tests. Therefore, bronchodilators were administered before every session and patients rinsed their mouth with water afterwards. It was observed that a significant drawback was the timing of administration of the drug formulation (60 minutes). Aerosol deposition was evaluated by radiolabeling, and remission of pulmonary function tests was observed after every chemotherapy session. In addition, other basic characteristics of this protocol proposal for inhalation chemotherapy were addressed, such as inclusion criteria. It is essential to highlight tumor size, which must not be more than $5 \mathrm{~cm}$ in mass median diameter, because this parameter is crucial for drug deposition. ${ }^{84,131}$ These issues are analyzed further in the safety section. In another study using nanoparticles with doxorubicin, it was observed that macrophages clear the formulation, so smaller nanoparticles need to be developed. ${ }^{47}$ Platinum analogs have also been investigated, and the findings were similar to those for inhaled doxorubicin. Moderate bronchospasm after aerosol inhalation, cough, fever 


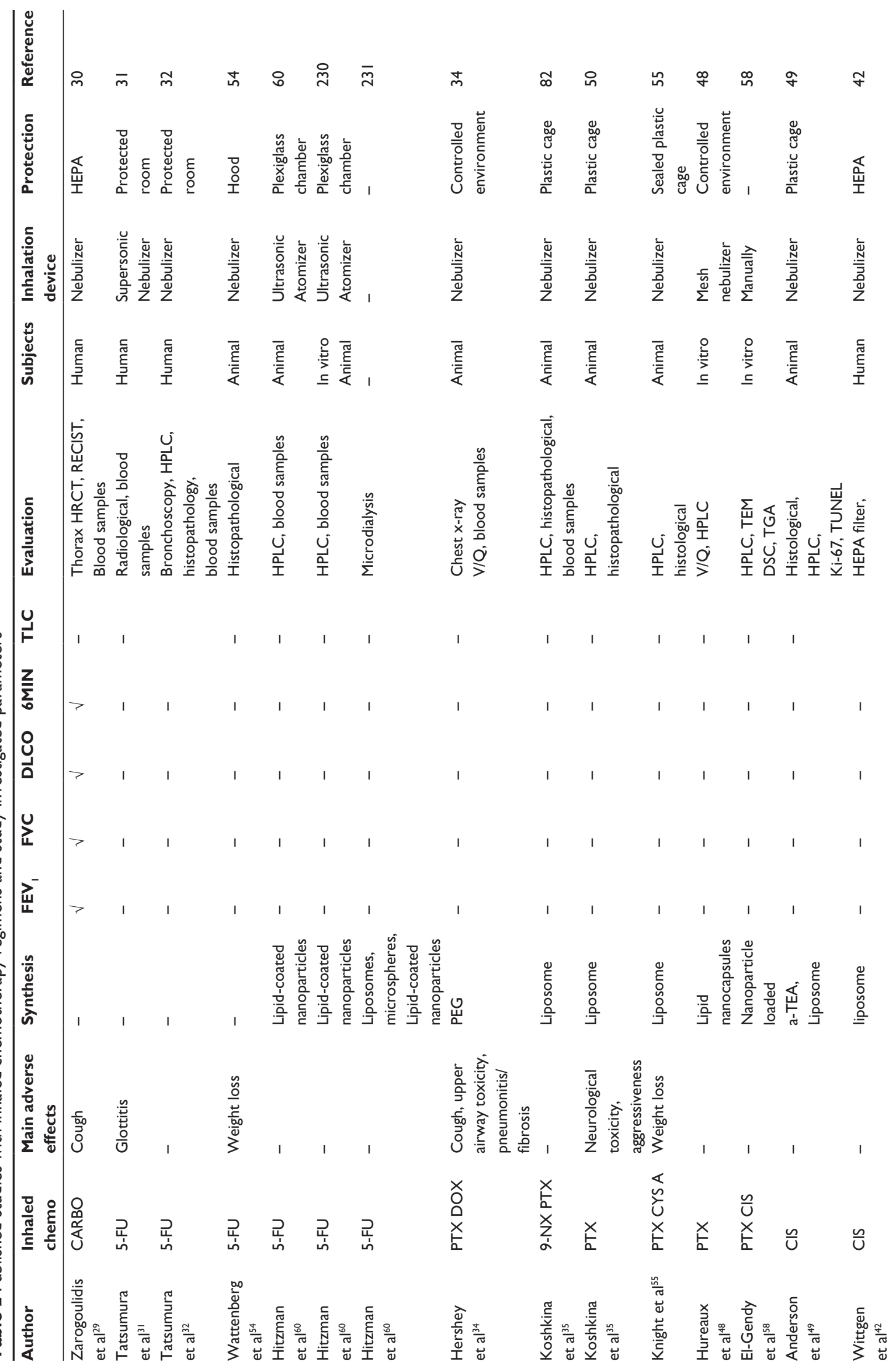



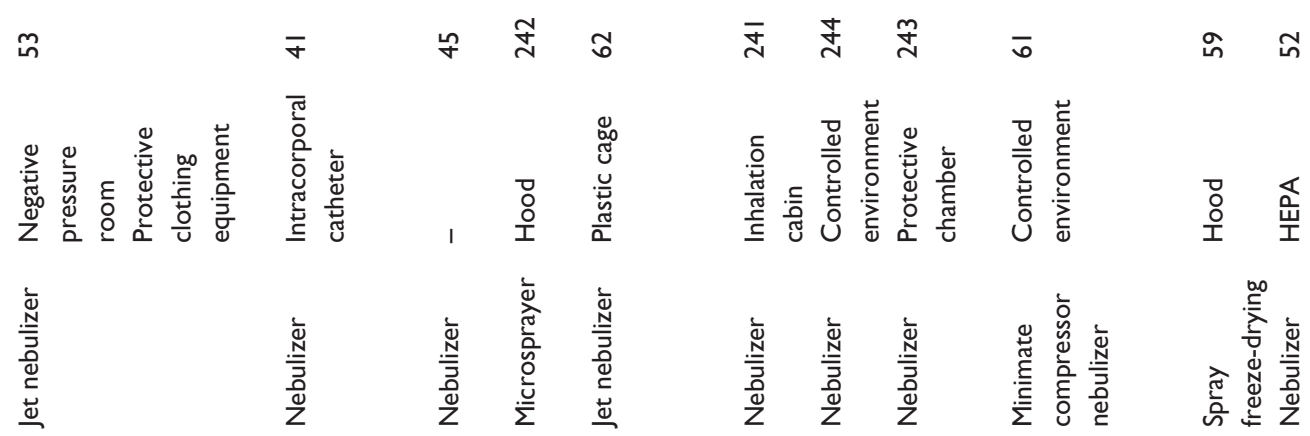

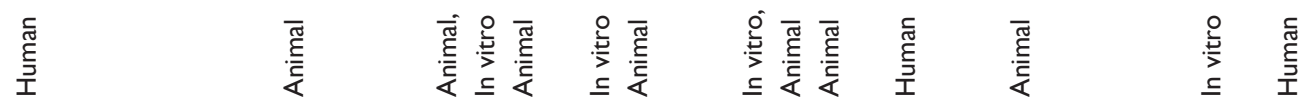
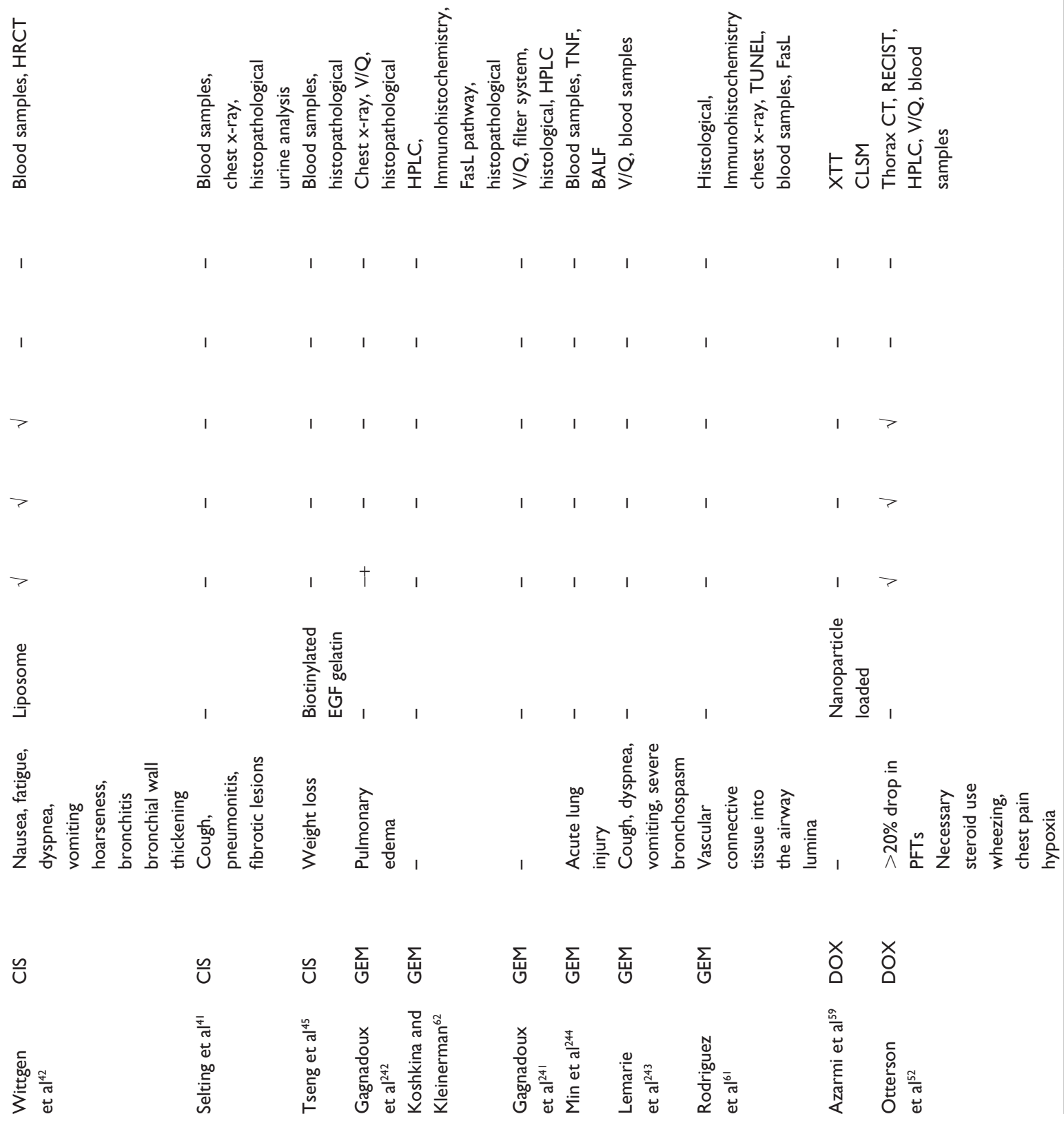


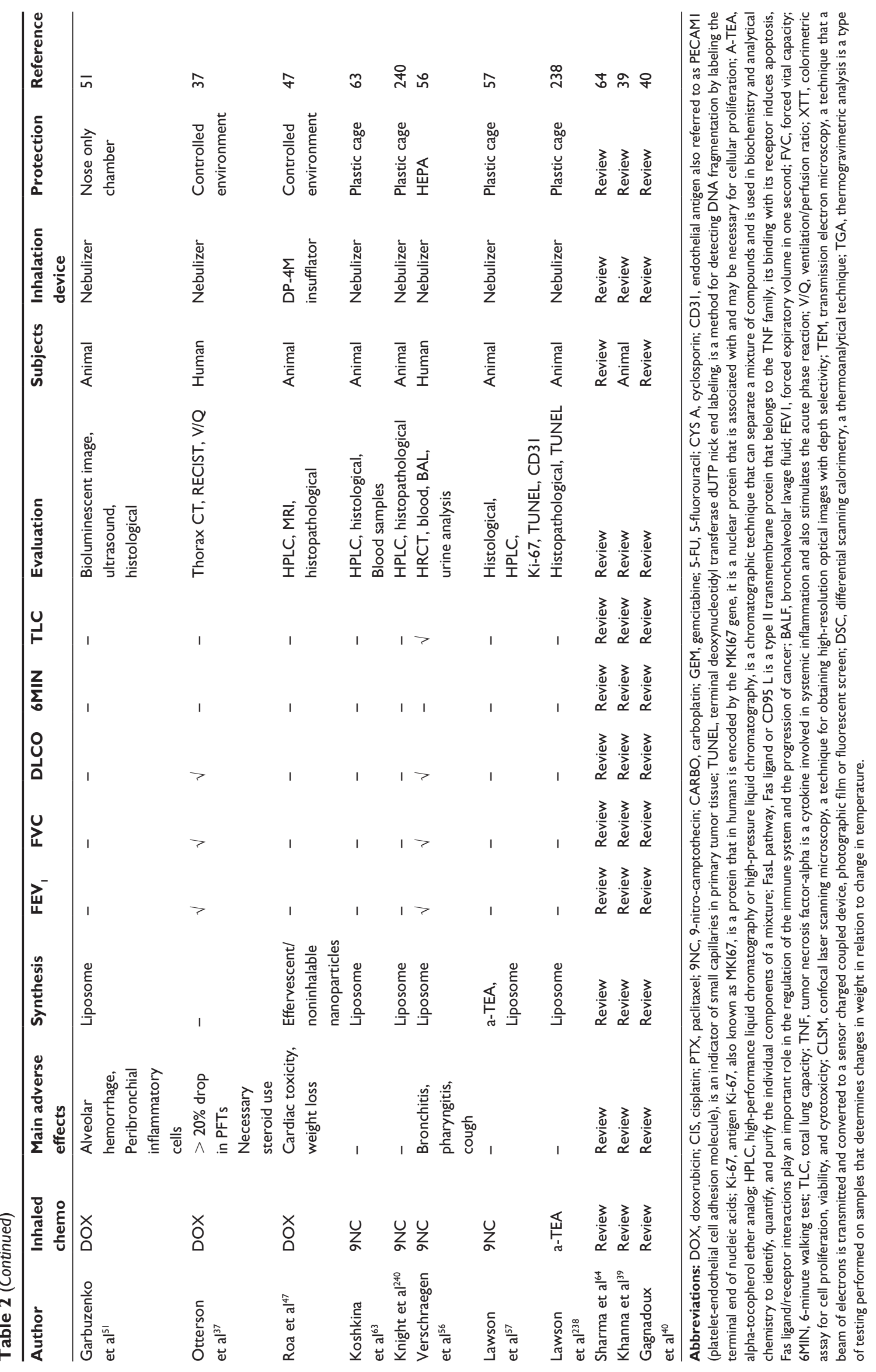


(three days in some cases), and a metallic taste were observed. Bronchodilators were administered before every session. Pulmonary function tests were also performed according to the American Thoracic Society/European Respiratory Society guidelines ${ }^{53,56,236,237}$ along with a high resolution CT scan of the thorax..$^{30,53}$ Mild reduction in pulmonary function tests was observed immediately after the chemotherapy session, but regressed until the next cycle.

In a study by Tseng et $\mathrm{al}^{45}$ a biotinylated epidermal growth factor-modified gelatin nanoparticle carrier was investigated, and found to enhance the anticancer activity of the formulation. In addition, it paved the way for targeted inhaled chemotherapy. Cancer cells with epidermal growth factor overexpression show increased uptake of this formulation. An additional benefit is reduced nephrotoxicity, because more cisplatin remains regionally in the lung cancer cells, and fewer carriers with cisplatin are delivered to the systemic circulation. Anderson et $\mathrm{al}^{49}$ administered a novel nonhydrolyzable ether-linked acetic acid analog of vitamin $\mathrm{E}$ (a-TEA) with intraperitoneal administration of cisplatin. This treatment is mentioned due to the positive effect observed in reducing lung metastasis to the lungs. ${ }^{49,238,239}$ The a-TEA could be used as a molecule additional to the aerosol formulation, in order to augment apoptosis of cancer cells and to decrease cancer cell proliferation. ${ }^{49,57,239}$ Again, safety issues are discussed in the safety section. The anticancer effect of 9-nitro-camptothecin as an aerosol has been established. ${ }^{56,57,240}$ Several formulations using carrier systems have been used to deliver sustained-release 9-nitro-camptothecin. Feasibility and effectiveness was established, and in addition to encapsulation with carriers, pegylation added a "stealth" property, as previously mentioned. The macrophages did not recognize the formulation and so did not attack, but cancer cells ingested the molecules due to the cationic charge (PEG technology). ${ }^{44}$ However, the polystyrene microparticles used in this study cannot be used in human subjects because they cannot be eliminated from the body. Therefore, an initiative to develop biocompatible aggregated nanogel particles has been started using additional PEG technology. ${ }^{44}$ In a study by Verschraegen et $\mathrm{al}^{56}$ aerosol therapy was taken to a level never previously achieved. After effectiveness and safety had been observed, patients were educated to receive their therapy at home. This study provides evidence that, if safety and effectiveness of such a system is confirmed, patients can receive any chemotherapy agent without having the side effects that are usually observed with these agents.

Gemcitabine, a well known chemotherapeutic agent, has been evaluated in dogs and baboons as an aerosol formulation. The formulation was radiolabeled and blood samples were collected until 360 minutes..$^{43,241,242}$ The efficacy of this treatment modality on lung metastasis due to osteosarcoma was investigated, along with Fas/FasL expression. The Fas ligand is a type II transmembrane protein that belongs to the tumor necrosis factor family. Fas expression in metastatic foci was increased compared with that in lung metastases before treatment, and at even higher levels than in the primary tumor. The results of these studies indicate that aerosolized gemcitabine treatment is effective against metastatic osteosarcoma lesions. ${ }^{61}$ Gemcitabine has been administered to patients with lung cancer, either as an aerosol or instilled into the lung parenchyma, and the data have demonstrated efficacy. ${ }^{243,244}$ The safety of gemcitabine in humans is discussed in the safety section.

\section{Safety and protection measures}

Both patients and medical staff should be considered concerning safety (Table 2). The question that needs to be answered is whether interstitial lung disease is induced due to inhalation chemotherapy. Several agents have been observed to induce this kind of damage after intravenous administration. ${ }^{245-251} \mathrm{On}$ high resolution CT, a ground-glass pattern, linear opacities, interlobular or intralobular thickening, and alveolar shadows were observed. Different histopathological appearances are also observed. Determining the background of pulmonary infiltrates in patients who develop pulmonary severe involvement while receiving chemotherapeutic agents can be problematic. There are several factors that could produce this type of appearance, including pulmonary edema, alveolar hemorrhage, involvement of background disease, and radiation. Moreover, a confirmatory biopsy or bronchoalveolar lavage is often not possible to undertake due to respiratory distress or severity of the underlying condition. Because several chemotherapeutic agents may induce interstitial lung disease by intravenous administration, a through safety evaluation has had to be performed for the aerolized formulations. Regarding the safety of medical personnel, the aerolized studies were performed with certain protection measures, including special plastic cages for animals. ${ }^{49,57}$ Other measures for protection were the design of the delivery system or method. In a number of studies, the drug was delivered through a special nose-only chamber ${ }^{51}$ and using an intracorporeal catheter. ${ }^{41}$ An evaluation of whether these systems had sufficient environment safety was performed in several cases and the measures were adequate. ${ }^{34}$

Evaluation of pulmonary toxicity was observed by post mortem histological examination and radiological 
investigations, ie, x-ray, magnetic resonance image, bioluminescent image, and V/Q scan. ${ }^{41,43,47,51}$ The most severe side effects were cough, weight loss, neurotoxicity, cardiotoxicity, alveolar interstitial pattern (radiological findings), moderate fibrosis (histopathological findings), and death as a result of pulmonary edema..$^{34,41,43,50,54}$ One death was reported in a Phase I study by Otterson et $\mathrm{al}^{52}$ after doxorubicin aerosol administration, but autopsy revealed focal hyaline membrane deposition and obstructive pneumonia due to tumor burden. Staphylococcus and Acinetobacter baumannii were isolated from blood cultures, two bacteria commonly found in intensive care units, where the patient had been hospitalized due to severe respiratory distress. Death was attributed to disease progression. Selting et $\mathrm{al}^{41}$ demonstrated clearly that when administered repeatedly to a specific part of the respiratory airway, platinum analogs moderate the fibrosis and an alveolar interstitial pattern occurs. Nevertheless, these findings are dose-associated and depend on the time interval of treatment. When bronchospasm occurred and there was a drop in pulmonary function tests, additional steroid treatment reversed these adverse effects. ${ }^{34,37,52}$ These lesions did not appear using liposomal paclitaxel in studies which included histopathological evaluation. ${ }^{55}$ In a study by Tseng et $\mathrm{al}^{45}$ less nephrotoxicity was observed with biotinylated epidermal growth factor-modified gelatin nanoparticle carriers with a platinum analog, in comparison with a free circulating platinum analog. Regarding human subjects, studies used either a mouthpiece ${ }^{30}$ or a facial mask $\mathrm{k}^{42,53,56}$ under a high efficiency particulate air system; the drug formulation which escaped (if any) was evaluated, and no toxic effects were found. In one study, the drug delivery system and formulation were evaluated and found to be efficient and safe enough that the patients were instructed to administer the drug formulation at home. ${ }^{56}$ Methods of evaluating the pulmonary parenchyma and respiratory capacity in human subjects have included pulmonary function tests with forced expiratory volume in one second $\left(\mathrm{FEV}_{1}\right)$, forced vital capacity, carbon monoxide diffusing capacity (DLCO), the 6-minute walking test, and high resolution CT or CT scan. ${ }^{30,37,52,53,56}$ The patients included in these studies did not have any known collagen disease in order to be certain whether interstitial disease findings, if observed, were due to the inhaled compound. The adverse effects most commonly observed were coughing, mild bronchoconstriction, fever, nausea, pharyngitis, thickening of the bronchial wall (high resolution CT finding), ${ }^{53}$ focal hyaline membrane deposition (post mortem finding), ${ }^{52}$ and reduction in pulmonary function tests that responded to corticosteroids or resolved after termination of treatment..$^{30,37,53}$ In a study
Table 3 Summary of inhaled chemotherapy in lung cancer

- Although there is a variety of inhalation devices available on the market, each one with advantages and disadvantages, administration of an inhaled chemotherapy formulation is currently feasible through a nebulization system.

- The aerosol compound time release can be enhanced by either adding a carrier which provides sustain release, or by adding $5 \%-7 \% \mathrm{CO}_{2}$ to the inhalable aerosol.

- Aerosol chemotherapy studies previously published provide conclusions with safety and feasibility of this treatment modality. Nevertheless, more trials are needed with patients of early stages to present long term data regarding adverse effects to the lung parenchyma. In addition, more single-agent or double-agent trials for the aerosol are needed to present indisputable data regarding the safety and effectiveness of this treatment modality in comparison with intravenous administration.

- A question remains whether this treatment modality is proper for early lung cancer stages or as neoadjuvant/adjuvant, since tumor size is a limitation for patients to be candidates.

- A new methodology of manipulating the aerosol deposition site according to cancer lesions has been proposed and developed, but is still under investigation.

- Inhaled chemotherapy has been evaluated in a number of studies (high efficiency particulate air system) and the results indicate that certain drug administration systems are efficient enough to eliminate diffuse/ spilling of the aerosolized agent to the environment. The next step of aerosol chemotherapy agent administered inhouse has also been tested successfully with proper education and use by patients.

- Administration of inhaled bronchodilators, corticosteroids, and $\mathrm{N}$-acetylcysteine could prevent and protect the lung parenchyma from adverse effects.

- The crucial question of whether such a treatment modality should be pursued will remain unanswered if further studies are not performed. The concept of a treatment modality for cancer patients free of systemic side effects is very tempting.

- This treatment modality in order to have widespread acceptance, solid data regarding the safety and feasibility needs to be pursued.

by Garbuzenko et $\mathrm{a}^{51}$ alveolar hemorrhage and bronchial accumulation of chronic inflammatory cells were observed in histopathological specimens after aerosol administration of liposomal doxorubicin. Moreover, large bronchi were surrounded by aggregates of chronic inflammatory cells, including lymphocytes, macrophages, and plasma cells. ${ }^{51}$ In three studies, a mild reduction of $\mathrm{FEV}_{1}$, forced vital capacity, and DLCO was observed after aerosol administration and therefore bronchodilators and inhaled corticosteroids were administered before every treatment. ${ }^{30,37,52,53}$ Gemcitabine in an aerosol formulation did not induce fibrotic lesions in the lung parenchyma and does not contain any chemical ingredients incompatible with aerosol delivery. ${ }^{43,62}$ Nevertheless, in an animal model, death from pulmonary edema occurred after aerosol administration of gemcitabine. ${ }^{43}$ Studies with 9-nitro-20(S)-camptothecin did not report fibrotic lesions 
in the lung parenchyma, although a reversible reduction in pulmonary function tests and mild adverse effects from the aerosol compound were observed (bronchial irritation, sore throat, pharyngitis). ${ }^{56}$ In studies performed in cancer cell lines, administration of the aerosol was conducted inside hoods, so medical personnel were safe from the toxic compounds. Assessment of efficacy was made by observing the decrease in the population of cancer cells. ${ }^{58,59}$

\section{Conclusion}

Inhaled chemotherapy is a feasible treatment modality. Nevertheless, the pulmonary side effects of this treatment have to be assessed further. Until now, inhaled chemotherapy was administered for advanced lung cancer and, therefore, although some chemotherapeutic agents provided immediate evidence of dose/time-related toxicity, others did not due to the limited duration of administration. Early-stage lung cancer studies did not administer inhaled chemotherapy for more than one session. ${ }^{31,32}$ Therefore, studies involving early-stage lung cancer are needed to provide time/dose-related safety data. Moreover, studies providing doublet inhaled chemotherapeutic agents need to be performed because doublet chemotherapy is the cornerstone of treatment for lung cancer. However, these trials should not be performed until sufficient data regarding the safety profile in the lung parenchyma are available. Regarding efficacy, regional studies have demonstrated positive results, but there are limitations to use of drug locoregionally according to tumor size, penetration of the drug at the tumor site, the chemical characteristics of the drug, and its biological effects. Regional therapy does not necessarily mean that higher drug levels reach the tumor. However, this concept contradicts the fact that, due to blood circulation in the lung ${ }^{52,53}$ and the lymphatic circulation, drug concentrations have been found in the systemic circulation and surgically resected lymph nodes. ${ }^{31,32,84,131,230,231,238}$ In addition, a high percentage of lymph nodes in the aerosol treatment groups did not show any metastasis in several studies, so it is possible that this route of administration destroys tumor cells and prevents them from trafficking from the primary subcutaneous tumor to the lungs and lymph nodes via the lymphatic system. ${ }^{31,32,49,57}$ Nevertheless, in many of these studies, an additional intravenous chemotherapy regimen was administered, so clear conclusions cannot be drawn. Nanoparticles have the ability to evade macrophages and transport them into lung tissues other than the alveolus and into the general circulation. ${ }^{47}$ However, macrophages are a defense mechanism that is also responsible for clearing the nanoparticles and, thus, reduce the anticancer effect of inhaled chemotherapy. Furthermore, an evaluation has to be made of whether inhaled chemotherapy is appropriate for early-stage lung cancer, or as neoadjuvant or adjuvant treatment. $57,60,61,230,231$

Because lesions are of smaller size, drug deposition is not prevented by the large mass median diameter of the tumor. ${ }^{131}$ Current drug delivery systems have demonstrated an ability to achieve sustained release locoregionally, but further improvement is welcomed. ${ }^{40,48,252}$ Nevertheless, the timing of the drug administration has to be shortened. ${ }^{30,48}$ Additional modifications were made to the molecules, to include targeted therapies, such as the epidermal growth factor receptor. ${ }^{45}$ In another study by Garbuzenko et a ${ }^{51}$ additional pump and nonpump suppressors were added to inhaled doxorubicin. This concept was based on the observation that there are two main mechanisms responsible for cancer cell chemotherapy resistance, ie, pump and nonpump..$^{253-255}$ Pump resistance is caused by membrane efflux pumps that decrease the anticancer drug concentration inside cells. Nonpump resistance is primarily attributed to the activation of antiapoptotic cellular defense, and Bcl-2 is also a key parameter in this defense. Similar to MRP 1, expression of Bcl-2 protein increases significantly after treatment with anticancer drugs. ${ }^{253,255}$ a-TEA could be used as a molecule additional to the aerosol formulation to augment apoptosis and decrease cancer cell proliferation. ${ }^{49,57,239}$ Nebulizers have also demonstrated efficiency for delivery and deposition of inhaled chemotherapeutic regimens. ${ }^{30,37,52,53}$ Additional modifications have been shown to improve deposition further by modifying respiratory rate and tidal volume. ${ }^{82}$ Delivery systems have been evaluated for safety regarding environmental release of toxins and it has been found that certain systems have the ability to deliver their entire drug cargo to patients, without any loss to the environment. ${ }^{30,42}$ Drug transporter gene expression appears to be high in the lungs. ${ }^{215}$ However, interaction of these genes with inhaled drug formulations, any alterations due to underlying respiratory disease, and their role in drug deposition are not fully explored. ${ }^{226}$ The transporters are less likely to influence absorption of inhaled drugs than they are to exert an effect in the gastrointestinal tract; nevertheless, efflux pumps can be exploited to prolong drug retention in situ. ${ }^{226}$ Transporter properties can be fully exploited if a formulation is designed for distribution to specific sites in the respiratory tract where they are highly expressed in combination with the appropriate drug carrier. In addition to the transporters, several other carriers have been investigated in combination with chemotherapy agents, either in order to make feasible 
their administration to the lung parenchyma for toxicity reasons, or to add a sustained-release capability to the lung formulation. ${ }^{34,39,40,47-51,53,55-60}$ Transporters could be used in addition as a prognostic factor. ${ }^{199}$ Moreover, regarding carriers, liposomes would appear to require dosing three or four times a day and would be expected to be well tolerated within the lung following repeated dosing. Microspheres and lipid-coated nanoparticles could be given once or twice daily, depending on particle residence time at the site of action. However, issues of particle accumulation within the alveoli may be encountered with repeated dosing. Due to the composition of lipid-coated nanoparticles in comparison with microspheres, there would be less of a concern with toxicity using lipid-coated nanoparticles. ${ }^{231}$ The optimal formulation for the clinician would be once-a-day delivery of a chemotherapy regimen, with the additional effect of pegylation for the "stealth" properties previously mentioned.

Finally, the next step in delivering inhaled chemotherapy at home has already been made after proper patient education, and the concept is intriguing. ${ }^{56}$ Monitoring of patients can be done using peak flow measurements at home between restaging, and addition of a combination of inhaled bronchodilators and corticosteroids before inhaled chemotherapy could help prevent adverse effects, such as bronchoconstriction. Addition of $\mathrm{N}$-acetylcysteine could be used as a protective measure. ${ }^{93,214}$ Finally, inhaled chemotherapy regimens when administered alone demonstrate fewer systemic cytotoxic effects, making the concept of safe inhaled chemotherapy the next challenge in the treatment of lung cancer. Nevertheless, the safety and efficacy of such formulations have yet to be fully and completely evaluated (Table 3).

\section{Disclosure}

The authors report no conflicts of interest in this work.

\section{References}

1. Jemal A, Bray F, Center MM, Ferlay J, Ward E, Forman D. Global cancer statistics. CA Cancer J Clin. 2011;61(2):69-90.

2. Langer CJ, Harris J, Horwitz EM, et al. Phase II study of low-dose paclitaxel and cisplatin in combination with split-course concomitant twice-daily reirradiation in recurrent squamous cell carcinoma of the head and neck: results of Radiation Therapy Oncology Group Protocol 9911. J Clin Oncol. 2007;25(30):4800-4805.

3. Curran WJ Jr, Schiller JH, Wolkin AC, Comis RL. Addressing the current challenges of non-small-cell lung cancer clinical trial accrual. Clin Lung Cancer. 2008;9(4):222-226.

4. Somer RA, Sherman E, Langer CJ. Restrictive eligibility limits access to newer therapies in non-small-cell lung cancer: the implications of Eastern Cooperative Oncology Group 4599. Clin Lung Cancer. 2008;9(2):102-105.

5. Novello S, Longo M, Levra MG. Toward therapies tailored to patient characteristics. J Thorac Oncol. 2007;2(Suppl 5):S38-S41.
6. Subramanian J, Waqar SN, Govindan R. Targeted therapy in lung cancer: lessons learned from past experiences. J Thorac Oncol. 2011; 6(11 Suppl 4):S1786-S1788.

7. Garcia Sar D, Aguado L, Montes Bayon M, et al. Relationships between cisplatin-induced adducts and DNA strand-breaks, mutation and recombination in vivo in somatic cells of Drosophila melanogaster, under different conditions of nucleotide excision repair. Mutat Res. 2012;741(1-2):81-88.

8. Hosomi Y, Shibuya M, Niho S, et al. Phase II study of topotecan with cisplatin in Japanese patients with small cell lung cancer. Anticancer Res. 2011;31(10):3449-3456.

9. Shepherd FA, Crowley J, Van Houtte P, et al. The International Association for the Study of Lung Cancer lung cancer staging project: proposals regarding the clinical staging of small cell lung cancer in the forthcoming (seventh) edition of the tumor, node, metastasis classification for lung cancer. J Thorac Oncol. 2007;2(12):1067-1077.

10. Hunter TB, Manimala NJ, Luddy KA, Catlin T, Antonia SJ. Paclitaxel and TRAIL synergize to kill paclitaxel-resistant small cell lung cancer cells through a caspase-independent mechanism mediated through AIF. Anticancer Res. 2011;31(10):3193-3204.

11. Schiller JH, Harrington D, Belani CP, et al. Comparison of four chemotherapy regimens for advanced non-small-cell lung cancer. $N$ Engl J Med. 2002;346(2):92-98.

12. Minchinton AI, Tannock IF. Drug penetration in solid tumours. Nat Rev Cancer. 2006;6(8):583-592.

13. Kemeny NE, Niedzwiecki D, Hollis DR, et al. Hepatic arterial infusion versus systemic therapy for hepatic metastases from colorectal cancer: a randomized trial of efficacy, quality of life, and molecular markers (CALGB 9481). J Clin Oncol. 2006;24(9):1395-1403.

14. Armstrong DK, Bundy B, Wenzel L, et al. Intraperitoneal cisplatin and paclitaxel in ovarian cancer. $N$ Engl J Med. 2006;354(1):34-43.

15. Guerin C, Olivi A, Weingart JD, Lawson HC, Brem H. Recent advances in brain tumor therapy: local intracerebral drug delivery by polymers. Invest New Drugs. 2004;22(1):27-37.

16. Robinson WR, Coberly C, Beyer J, Lewis A, Ballard C. Office-based intraperitoneal chemotherapy for ovarian cancer. J Oncol Pract. 2008; 4(5):225-228.

17. Hofstra LS, Bos AM, de Vries EG, et al. A phase I and pharmacokinetic study of intraperitoneal topotecan. Br J Cancer. 2001;85(11):1627-1633.

18. Osaki T, Hanagiri T, Nakanishi R, Yoshino I, Taga S, Yasumoto K. Bronchial arterial infusion is an effective therapeutic modality for centrally located early-stage lung cancer: results of a pilot study. Chest. 1999;115(5):1424-1428.

19. Maisch B, Ristic AD, Pankuweit S, Neubauer A, Moll R. Neoplastic pericardial effusion. Efficacy and safety of intrapericardial treatment with cisplatin. Eur Heart J. 2002;23(20):1625-1631.

20. Markman M, Cleary S, Pfeifle C, Howell SB. Cisplatin administered by the intracavitary route as treatment for malignant mesothelioma. Cancer. 1986;58(1):18-21.

21. Rusch VW, Figlin R, Godwin D, Piantadosi S. Intrapleural cisplatin and cytarabine in the management of malignant pleural effusions: a Lung Cancer Study Group trial. J Clin Oncol. 1991;9(2):313-319.

22. Goldberg EP, Hadba AR, Almond BA, Marotta JS. Intratumoral cancer chemotherapy and immunotherapy: opportunities for nonsystemic preoperative drug delivery. J Pharm Pharmacol. 2002;54(2): 159-180.

23. Duvillard C, Romanet P, Cosmidis A, Beaudouin N, Chauffert B. Phase 2 study of intratumoral cisplatin and epinephrine treatment for locally recurrent head and neck tumors. Ann Otol Rhinol Laryngol. 2004; 113(3 Pt 1):229-233.

24. Labiris NR, Dolovich MB. Pulmonary drug delivery. Part I: physiological factors affecting therapeutic effectiveness of aerosolized medications. Br J Clin Pharmacol. 2003;56(6):588-599.

25. Laube BL. The expanding role of aerosols in systemic drug delivery, gene therapy, and vaccination. Respir Care. 2005;50(9):1161-1176.

26. Bakker EM, Volpi S, Salonini E, et al. Improved treatment response to dornase alfa in cystic fibrosis patients using controlled inhalation. Eur Respir J. 2011;38(6):1328-1335. 
27. Bilton D, Robinson $\mathrm{P}$, Cooper $\mathrm{P}$, et al. Inhaled dry powder mannitol in cystic fibrosis: an efficacy and safety study. Eur Respir J. 2011;38(5): 1071-1080.

28. Yu KN, Minai-Tehrani A, Chang SH, et al. Aerosol delivery of small hairpin osteopontin blocks pulmonary metastasis of breast cancer in mice. PLoS One. 2010;5(12):e15623.

29. Zarogoulidis P, Papanas N, Kouliatsis G, Spyratos D, Zarogoulidis K, Maltezos E. Inhaled insulin: too soon to be forgotten? J Aerosol Med Pulm Drug Deliv. 2011;24(5):213-223.

30. Zarogoulidis P, Eleftheriadou E, Sapardanis I, et al. Feasibility and effectiveness of inhaled carboplatin in NSCLC patients. Invest New Drugs. July 8, 2011. [Epub ahead of print.]

31. Tatsumura T, Yamamoto K, Murakami A, Tsuda M, Sugiyama S. New chemotherapeutic method for the treatment of tracheal and bronchial cancers - nebulization chemotherapy. Gan No Rinsho. 1983;29(7): 765-770. Japanese.

32. Tatsumura T, Koyama S, Tsujimoto M, Kitagawa M, Kagamimori S. Further study of nebulisation chemotherapy, a new chemotherapeutic method in the treatment of lung carcinomas: fundamental and clinical Br J Cancer. 1993;68(6):1146-1149.

33. Gautam A, Koshkina N. Paclitaxel (Taxol) and taxoid derivates for lung cancer treatment: potential for aerosol delivery. Curr Cancer Drug Targets. 2003;3(4):287-296.

34. Hershey AE, Kurzman ID, Forrest LJ, et al. Inhalation chemotherapy for macroscopic primary or metastatic lung tumors: proof of principle using dogs with spontaneously occurring tumors as a model. Clin Cancer Res. 1999;5(9):2653-2659.

35. Koshkina NV, Golunski E, Roberts LE, Gilbert BE, Knight V. Cyclosporin A aerosol improves the anticancer effect of paclitaxel aerosol in mice. J Aerosol Med. 2004;17(1):7-14.

36. Minchin RF, Johnston MR, Aiken MA, Boyd MR. Pharmacokinetics of doxorubicin in isolated lung of dogs and humans perfused in vivo. J Pharmacol Exp Ther. 1984;229(1):193-198.

37. Otterson GA, Villalona-Calero MA, Hicks W, et al. Phase I/II study of inhaled doxorubicin combined with platinum-based therapy for advanced non-small cell lung cancer. Clin Cancer Res. 2010;16(8):2466-2473.

38. Gavini E, Manunta L, Giua S, Achenza G, Giunchedi P. Spray-dried poly(D,L-lactide) microspheres containing carboplatin for veterinary use: in vitro and in vivo studies. AAPS Pharm Sci Tech. 2005;6(1):E108-E114.

39. Khanna C, Vail DM. Targeting the lung: preclinical and comparative evaluation of anticancer aerosols in dogs with naturally occurring cancers. Curr Cancer Drug Targets. 2003;3(4):265-273.

40. Gagnadoux F, Hureaux J, Vecellio L, et al. Aerosolized chemotherapy. J Aerosol Med Pulm Drug Deliv. 2008;21(1):61-70.

41. Selting K, Waldrep JC, Reinero C, et al. Feasibility and safety of targeted cisplatin delivery to a select lung lobe in dogs via the AeroProbe intracorporeal nebulization catheter. J Aerosol Med Pulm Drug Deliv. 2008;21(3):255-268

42. Wittgen BP, Kunst PW, Perkins WR, Lee JK, Postmus PE. Assessing a system to capture stray aerosol during inhalation of nebulized liposomal cisplatin. J Aerosol Med. 2006;19(3):385-391.

43. Gagnadoux F, Pape AL, Lemarie E, et al. Aerosol delivery of chemotherapy in an orthotopic model of lung cancer. Eur Respir J. 2005;26(4): 657-661.

44. Chao P, Deshmukh M, Kutscher HL, et al. Pulmonary targeting microparticulate camptothecin delivery system: anticancer evaluation in a rat orthotopic lung cancer model. Anticancer Drugs. 2010;21(1):65-76.

45. Tseng CL, Su WY, Yen KC, Yang KC, Lin FH. The use of biotinylatedEGF-modified gelatin nanoparticle carrier to enhance cisplatin accumulation in cancerous lungs via inhalation. Biomaterials. 2009;30(20): 3476-3485.

46. Schaffer MW, Roy SS, Mukherjee S, Ong DE, Das SK. Uptake of all-trans retinoic acid-containing aerosol by inhalation to lungs in a guinea pig model system - a pilot study. Exp Lung Res. 2010;36(10):593-601.

47. Roa WH, Azarmi S, Al-Hallak MH, Finlay WH, Magliocco AM, Lobenberg R. Inhalable nanoparticles, a non-invasive approach to treat lung cancer in a mouse model. J Control Release. 2011;150(1):49-55.
48. Hureaux J, Lagarce F, Gagnadoux F, et al. Lipid nanocapsules: readyto-use nanovectors for the aerosol delivery of paclitaxel. Eur J Pharm Biopharm. 2009;73(2):239-246.

49. Anderson K, Lawson KA, Simmons-Menchaca M, Sun L, Sanders BG, Kline K. Alpha-TEA plus cisplatin reduces human cisplatin-resistant ovarian cancer cell tumor burden and metastasis. Exp Biol Med (Maywood). 2004;229(11):1169-1176.

50. Koshkina NV, Waldrep JC, Roberts LE, Golunski E, Melton S, Knight V. Paclitaxel liposome aerosol treatment induces inhibition of pulmonary metastases in murine renal carcinoma model. Clin Cancer Res. 2001;7(10):3258-3262.

51. Garbuzenko OB, Saad M, Pozharov VP, Reuhl KR, Mainelis G, Minko T. Inhibition of lung tumor growth by complex pulmonary delivery of drugs with oligonucleotides as suppressors of cellular resistance. Proc Natl Acad Sci U S A. 2010;107(23):10737-10742.

52. Otterson GA, Villalona-Calero MA, Sharma S, et al. Phase I study of inhaled doxorubicin for patients with metastatic tumors to the lungs. Clin Cancer Res. 2007;13(4):1246-1252.

53. Wittgen BP, Kunst PW, van der Born K, et al. Phase I study of aerosolized SLIT cisplatin in the treatment of patients with carcinoma of the lung. Clin Cancer Res. 2007;13(8):2414-2421.

54. Wattenberg LW, Wiedmann TS, Estensen RD. Chemoprevention of cancer of the upper respiratory tract of the Syrian golden hamster by aerosol administration of difluoromethylornithine and 5-fluorouracil. Cancer Res. 2004;64(7):2347-2349.

55. Knight V, Koshkina NV, Golunski E, Roberts LE, Gilbert BE. Cyclosporin A aerosol improves the anticancer effect of paclitaxel aerosol in mice. Trans Am Clin Climatol Assoc. 2004;115:395-404.

56. Verschraegen CF, Gilbert BE, Loyer E, et al. Clinical evaluation of the delivery and safety of aerosolized liposomal 9-nitro-20(s)-camptothecin in patients with advanced pulmonary malignancies. Clin Cancer Res. 2004;10(7):2319-2326.

57. Lawson KA, Anderson K, Snyder RM, et al. Novel vitamin E analogue and 9-nitro-camptothecin administered as liposome aerosols decrease syngeneic mouse mammary tumor burden and inhibit metastasis. Cancer Chemother Pharmacol. 2004;54(5):421-431.

58. El-Gendy N, Berkland C. Combination chemotherapeutic dry powder aerosols via controlled nanoparticle agglomeration. Pharm Res. 2009; 26(7):1752-1763.

59. Azarmi S, Tao X, Chen H, et al. Formulation and cytotoxicity of doxorubicin nanoparticles carried by dry powder aerosol particles. Int J Pharm. 2006;319(1-2):155-161.

60. Hitzman CJ, Wattenberg LW, Wiedmann TS. Pharmacokinetics of 5-fluorouracil in the hamster following inhalation delivery of lipidcoated nanoparticles. J Pharm Sci. 2006;95(6):1196-1211.

61. Rodriguez CO Jr, Crabbs TA, Wilson DW, et al. Aerosol gemcitabine: preclinical safety and in vivo antitumor activity in osteosarcoma-bearing dogs. J Aerosol Med Pulm Drug Deliv. 2010;23(4):197-206.

62. Koshkina NV, Kleinerman ES. Aerosol gemcitabine inhibits the growth of primary osteosarcoma and osteosarcoma lung metastases. Int $J$ Cancer. 2005;116(3):458-463.

63. Koshkina NV, Gilbert BE, Waldrep JC, Seryshev A, Knight V. Distribution of camptothecin after delivery as a liposome aerosol or following intramuscular injection in mice. Cancer Chemother Pharmacol. 1999;44(3):187-192.

64. Sharma S, White D, Imondi AR, Placke ME, Vail DM, Kris MG. Development of inhalational agents for oncologic use. J Clin Oncol. 2001;19(6):1839-1847.

65. Swift DL. Aerosols and humidity therapy. Generation and respiratory deposition of therapeutic aerosols. Am Rev Respir Dis. 1980; 122(5 Pt 2):71-77.

66. Phipps PR, Gonda I, Anderson SD, Bailey D, Bautovich G. Regional deposition of saline aerosols of different tonicities in normal and asthmatic subjects. Eur Respir J. 1994;7(8):1474-1482.

67. Shinohara H. Distribution of lymphatic stomata on the pleural surface of the thoracic cavity and the surface topography of the pleural mesothelium in the golden hamster. Anat Rec. 1997;249(1):16-23. 
68. Lai-Fook SJ. Mechanical factors in lung liquid distribution. Annu Rev Physiol. 1993;55:155-179.

69. Nunn JF. Nunn's Applied Respiratory Physiology. 4th ed. Oxford, UK: Butterworth-Heineman; 1993.

70. Deffebach ME, Charan NB, Lakshminarayan S, Butler J. The bronchial circulation. Small, but a vital attribute of the lung. Am Rev Respir Dis. 1987;135(2):463-481.

71. Houtmeyers E, Gosselink R, Gayan-Ramirez G, Decramer M. Regulation of mucociliary clearance in health and disease. Eur Respir J. 1999;13(5):1177-1188.

72. Summers QA. Inhaled drugs and the lung. Clin Exp Allergy. 1991;21(3): 259-268.

73. Stone KC, Mercer RR, Gehr P, Stockstill B, Crapo JD. Allometric relationships of cell numbers and size in the mammalian lung. Am J Respir Cell Mol Biol. 1992;6(2):235-243.

74. Folkesson HG, Matthay MA, Westrom BR, Kim KJ, Karlsson BW, Hastings RH. Alveolar epithelial clearance of protein. J Appl Physiol. 1996;80(5):1431-1445.

75. Martonen TB. Mathematical model for the selective deposition of inhaled pharmaceuticals. J Pharm Sci. 1993;82(12):1191-1199.

76. Suarez S, Hickey AJ. Drug properties affecting aerosol behavior. Respir Care. 2000;45(6):652-666.

77. Ilowite JS, Gorvoy JD, Smaldone GC. Quantitative deposition of aerosolized gentamicin in cystic fibrosis. Am Rev Respir Dis. 1987;136(6): 1445-1449.

78. Messina MS, Smaldone GC. Evaluation of quantitative aerosol techniques for use in bronchoprovocation studies. J Allergy Clin Immunol. 1985;75(2):252-257.

79. Dolovich MB, Killian D, Wolff RK, Obminski G, Newhouse MT. Pulmonary aerosol deposition in chronic bronchitis: intermittent positive pressure breathing versus quiet breathing. Am Rev Respir Dis. 1977; 115(3):397-402.

80. Dolovich MB, Sanchis J, Rossman C, Newhouse MT. Aerosol penetrance: a sensitive index of peripheral airways obstruction. $J \mathrm{Appl}$ Physiol. 1976;40(3):468-471.

81. Davis JN, Stagg D. Interrelationships of the volume and time components of individual breaths in resting man. J Physiol. 1975;245(2): 481-498.

82. Koshkina NV, Knight V, Gilbert BE, Golunski E, Roberts L, Waldrep JC. Improved respiratory delivery of the anticancer drugs, camptothecin and paclitaxel, with 5\% CO2-enriched air: pharmacokinetic studies. Cancer Chemother Pharmacol. 2001;47(5):451-456.

83. Stegen K, Neujens A, Crombez G, Hermans D, Van de Woestijne KP, Van den Bergh O. Negative affect, respiratory reactivity, and somatic complaints in a $\mathrm{CO} 2$ enriched air inhalation paradigm. Biol Psychol. 1998;49(1-2):109-122.

84. Kleinstreuer C, Zhang Z, Li Z. Modeling airflow and particle transport/deposition in pulmonary airways. Respir Physiol Neurobiol. 2008;163(1-3):128-138.

85. Zhang Z, Kleinstreuer C, Kim CS. Airflow and nanoparticle deposition in a 16-generation tracheobronchial airway model. Ann Biomed Eng. 2008;36(12):2095-2110.

86. Crank J. The Mathematics of Diffusion. 2nd ed. Oxford, UK: Clarendon Press; 1975.

87. Leu AJ, Berk DA, Lymboussaki A, Alitalo K, Jain RK. Absence of functional lymphatics within a murine sarcoma: a molecular and functional evaluation. Cancer Res. 2000;60(16):4324-4327.

88. Jain RK, Munn LL, Fukumura D. Dissecting tumour pathophysiology using intravital microscopy. Nat Rev Cancer. 2002;2(4):266-276.

89. Jain RK. Delivery of molecular and cellular medicine to solid tumors. Adv Drug Deliv Rev. 1997;26(2-3):71-90.

90. Milosevic MF, Fyles AW, Wong R, et al. Interstitial fluid pressure in cervical carcinoma: within tumor heterogeneity, and relation to oxygen tension. Cancer. 1998;82(12):2418-2426.

91. Heldin $\mathrm{CH}$, Rubin K, Pietras K, Ostman A. High interstitial fluid pressure - an obstacle in cancer therapy. Nat Rev Cancer. 2004;4(10): 806-813.
92. Jain RK. Barriers to drug delivery in solid tumors. Sci Am. 1994;271(1): 58-65.

93. Jain RK. Transport of molecules in the tumor interstitium: a review. Cancer Res. 1987;47(12):3039-3051.

94. Weber A, Morlin G, Cohen M, Williams-Warren J, Ramsey B, Smith A. Effect of nebulizer type and antibiotic concentration on device performance. Pediatr Pulmonol. 1997;23(4):249-260.

95. Eschenbacher WL, Boushey HA, Sheppard D. Alteration in osmolarity of inhaled aerosols cause bronchoconstriction and cough, but absence of a permeant anion causes cough alone. Am Rev Respir Dis. 1984; 129(2):211-215

96. Jonas DE, Wines RCM, DelMonte M, et al. Drug Class Review: Controller Medications for Asthma: Final Update 1 Report. Portland, OR: Oregon Health \& Science University; 2011.

97. Dolovich MB, Ramsdale EH. Replacing CFC aerosols with powders. CMAJ. 1990;142(10):1036.

98. Newman SP. Therapeutic inhalation agents and devices. Effectiveness in asthma and bronchitis. Postgrad Med. 1984;76(5):194-203.

99. Bennett WD, Smaldone GC. Human variation in the peripheral airspace deposition of inhaled particles. J Appl Physiol. 1987;62(4): 1603-1610.

100. Dolovich M, Ryan G, Newhouse MT. Aerosol penetration into the lung; influence on airway responses. Chest. 1981;80(Suppl 6):834-836.

101. Crompton GK. Problems patients have using pressurized aerosol inhalers. Eur J Respir Dis Suppl. 1982;119:101-104.

102. Newman SP, Pavia D, Moren F, Sheahan NF, Clarke SW. Deposition of pressurised aerosols in the human respiratory tract. Thorax. 1981; 36(1):52-55.

103. Newman SP, Pavia D, Garland N, Clarke SW. Effects of various inhalation modes on the deposition of radioactive pressurized aerosols. Eur J Respir Dis Suppl. 1982;119:57-65.

104. Pavia D, Thomson ML, Clarke SW, Shannon HS. Effect of lung function and mode of inhalation on penetration of aerosol into the human lung. Thorax. 1977;32(2):194-197.

105. Newman SP, Weisz AW, Talaee N, Clarke SW. Improvement of drug delivery with a breath actuated pressurised aerosol for patients with poor inhaler technique. Thorax. 1991;46(10):712-716.

106. Chapman KR, Love L, Brubaker H. A comparison of breath-actuated and conventional metered-dose inhaler inhalation techniques in elderly subjects. Chest. 1993;104(5):1332-1337.

107. Dolovich M. Rationale for spacer use in children. Pediatr Pulmonol Suppl. 1997;16:184-185.

108. Pedersen S. Inhalers and nebulizers: which to choose and why. Respir Med. 1996;90(2):69-77.

109. Dolovich M. New propellant-free technologies under investigation. J Aerosol Med. 1999;12 Suppl 1:S9-S17.

110. Newman SP, Moren F, Trofast E, Talaee N, Clarke SW. Deposition and clinical efficacy of terbutaline sulphate from Turbuhaler, a new multi-dose powder inhaler. Eur Respir J. 1989;2(3): 247-252.

111. Labiris NR, Dolovich MB. Pulmonary drug delivery. Part II: the role of inhalant delivery devices and drug formulations in therapeutic effectiveness of aerosolized medications. Br J Clin Pharmacol. 2003; 56(6):600-612.

112. Borgstrom L, Bondesson E, Moren F, Trofast E, Newman SP. Lung deposition of budesonide inhaled via Turbuhaler: a comparison with terbutaline sulphate in normal subjects. Eur Respir J. 1994;7(1):69-73.

113. Clark AR, Hollingworth AM. The relationship between powder inhaler resistance and peak inspiratory conditions in healthy volunteers implications for in vitro testing. J Aerosol Med. Summer 1993;6(2): 99-110.

114. Chrystyn H. Is inhalation rate important for a dry powder inhaler? Using the In-Check Dial to identify these rates. Respir Med. 2003; 97(2):181-187.

115. Lavorini F, Magnan A, Dubus JC, et al. Effect of incorrect use of dry powder inhalers on management of patients with asthma and COPD. Respir Med. 2008;102(4):593-604. 
116. Amani A, York P, Chrystyn H, Clark BJ, Do DQ. Determination of factors controlling the particle size in nanoemulsions using artificial neural networks. Eur J Pharm Sci. 2008;35(1-2):42-51.

117. Dolovich MB, Ahrens RC, Hess DR, et al. Device selection and outcomes of aerosol therapy: Evidence-based guidelines: American College of Chest Physicians/American College of Asthma, Allergy, and Immunology. Chest. 2005;127(1):335-371.

118. Kendrick AH, Smith EC, Wilson RS. Selecting and using nebuliser equipment. Thorax. 1997;52 Suppl 2:S92-S101.

119. Boe J, Dennis JH, O’Driscoll BR, et al. European Respiratory Society Guidelines on the use of nebulizers. Eur Respir J. 2001;18(1):228-242.

120. Smith EC, Denyer J, Kendrick AH. Comparison of twenty three nebulizer/compressor combinations for domiciliary use. Eur Respir J. 1995;8(7):1214-1221.

121. Brand P, Beckmann H, Maas Enriquez M, et al. Peripheral deposition of alpha1-protease inhibitor using commercial inhalation devices. Eur Respir J. 2003;22(2):263-267.

122. Niven RW, Ip AY, Mittelman S, Prestrelski SJ, Arakawa T. Some factors associated with the ultrasonic nebulization of proteins. Pharm Res. 1995;12(1):53-59.

123. Wagner A, Vorauer-Uhl K, Katinger H. Nebulization of liposomal rh-Cu/Zn-SOD with a novel vibrating membrane nebulizer. J Liposome Res. 2006;16(2):113-125.

124. Elhissi AM, Karnam KK, Danesh-Azari MR, Gill HS, Taylor KM. Formulations generated from ethanol-based proliposomes for delivery via medical nebulizers. J Pharm Pharmacol. 2006;58(7):887-894.

125. Kleemann E, Schmehl T, Gessler T, Bakowsky U, Kissel T, Seeger W. Iloprost-containing liposomes for aerosol application in pulmonary arterial hypertension: formulation aspects and stability. Pharm Res. 2007;24(2):277-287.

126. Johnson JC, Waldrep JC, Guo J, Dhand R. Aerosol delivery of recombinant human DNase I: in vitro comparison of a vibrating-mesh nebulizer with a jet nebulizer. Respir Care. 2008;53(12):1703-1708.

127. Smaldone GC, Berg E, Nikander K. Variation in pediatric aerosol delivery: importance of facemask. J Aerosol Med. 2005;18(3):354-363.

128. Harris KW, Smaldone GC. Facial and ocular deposition of nebulized budesonide: effects of face mask design. Chest. 2008;133(2):482-488.

129. Smaldone GC, Sangwan S, Shah A. Facemask design, facial deposition, and delivered dose of nebulized aerosols. J Aerosol Med. 2007; 20 Suppl 1:S66-S75.

130. Erzinger S, Schueepp KG, Brooks-Wildhaber J, Devadason SG, Wildhaber JH. Facemasks and aerosol delivery in vivo. $J$ Aerosol Med. 2007;20 Suppl 1:S78-S83.

131. Kleinstreuer C, Zhang Z, Donohue JF. Targeted drug-aerosol delivery in the human respiratory system. Annu Rev Biomed Eng. 2008;10: 195-220.

132. Dunne A, O'Hara T, Devane J. A new approach to modelling the relationship between in vitro and in vivo drug dissolution/absorption. Stat Med. 1999;18(14):1865-1876.

133. Zierenberg B. Optimizing the in vitro performance of Respimat J Aerosol Med. 1999;12 Suppl 1:S19-S24.

134. Newman SP, Steed KP, Reader SJ, Hooper G, Zierenberg B. Efficient delivery to the lungs of flunisolide aerosol from a new portable handheld multidose nebulizer. J Pharm Sci. 1996;85(9):960-964.

135. Newman SP, Brown J, Steed KP, Reader SJ, Kladders H. Lung deposition of fenoterol and flunisolide delivered using a novel device for inhaled medicines: comparison of RESPIMAT with conventional metered-dose inhalers with and without spacer devices. Chest. 1998; 113(4):957-963.

136. Bateman ED, Tashkin D, Siafakas N, et al. A one-year trial of tiotropium Respimat plus usual therapy in COPD patients. Respir Med. 2010;104(10):1460-1472.

137. Storm G, Crommelin DJ. Colloidal systems for tumor targeting. Hybridoma. 1997;16(1):119-125.

138. Suarez S, Gonzalez-Rothi RJ, Schreier H, Hochhaus G. Effect of dose and release rate on pulmonary targeting of liposomal triamcinolone acetonide phosphate. Pharm Res. 1998;15(3):461-465.
139. Fielding RM,AbraRM. Factors affecting the release rate of terbutaline from liposome formulations after intratracheal instillation in the guinea pig. Pharm Res. 1992;9(2):220-223.

140. Cryan SA. Carrier-based strategies for targeting protein and peptide drugs to the lungs. AAPS J. 2005;7(1):E20-E41.

141. Gonzalez-Rothi RJ, Suarez S, Hochhaus G, et al. Pulmonary targeting of liposomal triamcinolone acetonide phosphate. Pharm Res. 1996; 13(11):1699-1703.

142. Gonzalez-Rothi RJ, Straub L, Cacace JL, Schreier H. Liposomes and pulmonary alveolar macrophages: functional and morphologic interactions. Exp Lung Res. 1991;17(4):687-705.

143. Lasic DD. Liposomes in Gene Delivery. Boca Raton, FL: CRC Press; 1997.

144. Allen TM. Liposomal drug formulations. Rationale for development and what we can expect for the future. Drugs. 1998;56(5):747-756.

145. Schreier H, Gagne L, Bock T, et al. Physicochemical properties and in vitro toxicity of cationic liposome cDNA complexes. Pharm Acta Helv. 1997;72(4):215-223.

146. Niven RW, Schreier H. Nebulization of liposomes. I. Effects of lipid composition. Pharm Res. 1990;7(11):1127-1133.

147. Desai TR, Hancock RE, Finlay WH. A facile method of delivery of liposomes by nebulization. $J$ Control Release. 2002;84(1-2):69-78.

148. Niven RW, Speer M, Schreier H. Nebulization of liposomes. II. The effects of size and modeling of solute release profiles. Pharm Res. 1991;8(2):217-221.

149. Niven RW, Carvajal TM, Schreier H. Nebulization of liposomes. III. The effects of operating conditions and local environment. Pharm Res. 1992;9(4):515-520.

150. Joshi M, Misra A. Dry powder inhalation of liposomal ketotifen fumarate: formulation and characterization. Int J Pharm. 2001;223(1-2): $15-27$.

151. Skalko-Basnet N, Pavelic Z, Becirevic-Lacan M. Liposomes containing drug and cyclodextrin prepared by the one-step spray-drying method. Drug Dev Ind Pharm. 2000;26(12):1279-1284.

152. Omri A, Beaulac C, Bouhajib M, Montplaisir S, Sharkawi M, Lagace J. Pulmonary retention of free and liposome-encapsulated tobramycin after intratracheal administration in uninfected rats and rats infected with Pseudomonas aeruginosa. Antimicrob Agents Chemother. 1994; 38(5):1090-1095.

153. Woodle MC, Collins LR, Sponsler E, Kossovsky N, Papahadjopoulos D, Martin FJ. Sterically stabilized liposomes. Reduction in electrophoretic mobility but not electrostatic surface potential. Biophys J. 1992;61(4): 902-910.

154. Deol P, Khuller GK. Lung specific stealth liposomes: stability, biodistribution and toxicity of liposomal antitubercular drugs in mice. Biochim Biophys Acta. 1997;1334(2-3):161-172.

155. Hutchinson FG, Furr BJ. Biodegradable polymers for controlled release of peptides and proteins. Horiz Biochem Biophys. 1989;9:111-129.

156. Ehrhardt C, Fiegel J, Fuchs S, et al. Drug absorption by the respiratory mucosa: cell culture models and particulate drug carriers. $J$ Aerosol Med. 2002;15(2):131-139.

157. Kawashima Y, Yamamoto H, Takeuchi H, Fujioka S, Hino T. Pulmonary delivery of insulin with nebulized DL-lactide/glycolide copolymer (PLGA) nanospheres to prolong hypoglycemic effect. $J$ Control Release. 1999;62(1-2):279-287.

158. Cheng YS, Yazzie D, Gao J, Muggli D, Etter J, Rosenthal GJ. Particle characteristics and lung deposition patterns in a human airway replica of a dry powder formulation of polylactic acid produced using supercritical fluid technology. J Aerosol Med. 2003;16(1):65-73.

159. Dhiman N, Khuller GK. Protective efficacy of mycobacterial 71-kDa cell wall associated protein using poly (DL-lactide-co-glycolide) microparticles as carrier vehicles. FEMS Immunol Med Microbiol. 1998;21(1):19-28.

160. Evora C, Soriano I, Rogers RA, Shakesheff KN, Hanes J, Langer R. Relating the phagocytosis of microparticles by alveolar macrophages to surface chemistry: the effect of 1,2-dipalmitoylphosphatidylcholine. J Control Release. 1998;51(2-3):143-152. 
161. Fiegel J, Ehrhardt C, Schaefer UF, Lehr CM, Hanes J. Large porous particle impingement on lung epithelial cell monolayers - toward improved particle characterization in the lung. Pharm Res. 2003;20(5): 788-796.

162. Bittner B, Kissel T. Ultrasonic atomization for spray drying: a versatile technique for the preparation of protein loaded biodegradable microspheres. J Microencapsul. 1999;16(3):325-341.

163. Takeuchi H, Yamamoto H, Kawashima Y. Mucoadhesive nanoparticulate systems for peptide drug delivery. Adv Drug Deliv Rev. 2001; 47(1):39-54.

164. Langer R. Drug delivery and targeting. Nature. 1998;392(Suppl 6679): $5-10$.

165. Tsapis N, Bennett D, Jackson B, Weitz DA, Edwards DA. Trojan particles: large porous carriers of nanoparticles for drug delivery. Proc Natl Acad Sci U S A. 2002;99(19):12001-12005.

166. Edwards DA, Hanes J, Caponetti G, et al. Large porous particles for pulmonary drug delivery. Science. 1997;276(5320):1868-1871.

167. Cannon GJ, Swanson JA. The macrophage capacity for phagocytosis. J Cell Sci. 1992;101(Pt 4):907-913.

168. Steckel H, Bolzen N. Alternative sugars as potential carriers for dry powder inhalations. Int J Pharm. 2004;270(1-2):297-306.

169. Kobayashi S, Kondo S, Juni K. Pulmonary delivery of salmon calcitonin dry powders containing absorption enhancers in rats. Pharm Res. 1996;13(1):80-83.

170. Winters MA, Knutson BL, Debenedetti PG, et al. Precipitation of proteins in supercritical carbon dioxide. J Pharm Sci. 1996;85(6):586-594.

171. Sellers SP, Clark GS, Sievers RE, Carpenter JF. Dry powders of stable protein formulations from aqueous solutions prepared using supercritical CO(2)-assisted aerosolization. J Pharm Sci. 2001;90(6):785-797.

172. Hickey WA. Factors influencing the distortion of sex ratio in Aedes aegypti. J Med Entomol. 1970;7(6):727-735.

173. Maa YF, Nguyen PA, Sweeney T, Shire SJ, Hsu CC. Protein inhalation powders: spray drying vs spray freeze drying. Pharm Res. 1999;16(2): 249-254.

174. Klink DT, Chao S, Glick MC, Scanlin TF. Nuclear translocation of lactosylated poly-L-lysine/cDNA complex in cystic fibrosis airway epithelial cells. Mol Ther. 2001;3(6):831-841.

175. Kawashima Y, Serigano T, Hino T, Yamamoto H, Takeuchi H. A new powder design method to improve inhalation efficiency of pranlukast hydrate dry powder aerosols by surface modification with hydroxypropylmethylcellulose phthalate nanospheres. Pharm Res. 1998;15(11): 1748-1752.

176. Rajewski RA, Stella VJ. Pharmaceutical applications of cyclodextrins. 2. In vivo drug delivery. J Pharm Sci. 1996;85(11):1142-1169.

177. Woodle MC, Scaria P, Ganesh S, et al. Sterically stabilized polyplex: ligand-mediated activity. J Control Release. 2001;74(1-3):309-311.

178. Klonne DR, Dodd DE, Losco PE, Troup CM, Tyler TR. Two-week aerosol inhalation study on polyethylene glycol (PEG) 3350 in F-344 rats. Drug Chem Toxicol. 1989;12(1):39-48.

179. Zhang L, Zhu W, Song L, et al. Effects of hydroxylpropyl-betacyclodextrin on in vitro insulin stability. Int J Mol Sci. 2009;10(5): 2031-2040.

180. Bruck A, Abu-Dahab R, Borchard G, Schafer UF, Lehr CM. Lectin-functionalized liposomes for pulmonary drug delivery: interaction with human alveolar epithelial cells. J Drug Target. 2001;9(4):241-251.

181. Abu-Dahab R, Schafer UF, Lehr CM. Lectin-functionalized liposomes for pulmonary drug delivery: effect of nebulization on stability and bioadhesion. Eur J Pharm Sci. 2001;14(1):37-46.

182. Yi SM, Harson RE, Zabner J, Welsh MJ. Lectin binding and endocytosis at the apical surface of human airway epithelia. Gene Ther. 2001;8(24):1826-1832.

183. Kloss A, Henklein P, Siele D, et al. The cell-penetrating peptide octaarginine is a potent inhibitor of proteasome activities. Eur J Pharm Biopharm. 2009;72(1):219-225.

184. Strayer MS, Guttentag SH, Ballard PL. Targeting type II and Clara cells for adenovirus-mediated gene transfer using the surfactant protein B promoter. Am J Respir Cell Mol Biol. 1998;18(1):1-11.
185. Goren D, Horowitz AT, Tzemach D, Tarshish M, Zalipsky S, Gabizon A. Nuclear delivery of doxorubicin via folate-targeted liposomes with bypass of multidrug-resistance efflux pump. Clin Cancer Res. 2000; 6(5):1949-1957.

186. Cristiano RJ, Roth JA. Epidermal growth factor mediated DNA delivery into lung cancer cells via the epidermal growth factor receptor. Cancer Gene Ther. 1996;3(1):4-10.

187. Lundberg M, Wikstrom S, Johansson M. Cell surface adherence and endocytosis of protein transduction domains. Mol Ther. 2003;8(1):143-150.

188. Derossi D, Calvet S, Trembleau A, Brunissen A, Chassaing G, Prochiantz A. Cell internalization of the third helix of the Antennapedia homeodomain is receptor-independent. J Biol Chem. 1996;271(30): 18188-18193.

189. Kurten RC. Sorting motifs in receptor trafficking. Adv Drug Deliv Rev. 2003;55(11):1405-1419.

190. Hasegawa S, Hirashima N, Nakanishi M. Microtubule involvement in the intracellular dynamics for gene transfection mediated by cationic liposomes. Gene Ther. 2001;8(21):1669-1673.

191. Leslie EM, Deeley RG, Cole SP. Multidrug resistance proteins: role of P-glycoprotein, MRP1, MRP2, and BCRP (ABCG2) in tissue defense. Toxicol Appl Pharmacol. 2005;204(3):216-237.

192. Sharom FJ. ABC multidrug transporters: structure, function and role in chemoresistance. Pharmacogenomics. 2008;9(1):105-127.

193. Zhang L, Strong JM, Qiu W, Lesko LJ, Huang SM. Scientific perspectives on drug transporters and their role in drug interactions. Mol Pharm. 2006;3(1):62-69.

194. Lechapt-Zalcman E, Hurbain I, Lacave R, et al. MDR1-Pgp 170 expression in human bronchus. Eur Respir J. 1997;10(8):1837-1843.

195. Scheffer GL, Pijnenborg AC, Smit EF, et al. Multidrug resistance related molecules in human and murine lung. J Clin Pathol. 2002; 55(5):332-339.

196. van der Valk P, van Kalken CK, Ketelaars H, et al. Distribution of multi-drug resistance-associated P-glycoprotein in normal and neoplastic human tissues. Analysis with 3 monoclonal antibodies recognizing different epitopes of the P-glycoprotein molecule. Ann Oncol. 1990;1(1):56-64.

197. Cordon-Cardo C, O'Brien JP, Boccia J, Casals D, Bertino JR, Melamed MR. Expression of the multidrug resistance gene product (P-glycoprotein) in human normal and tumor tissues. J Histochem Cytochem. 1990;38(9):1277-1287.

198. Schinkel AH, Jonker JW. Mammalian drug efflux transporters of the ATP binding cassette (ABC) family: an overview. Adv Drug Deliv Rev. 2003;55(1):3-29.

199. Hsia TC, Lin CC, Wang JJ, Ho ST, Kao A. Relationship between chemotherapy response of small cell lung cancer and P-glycoprotein or multidrug resistance-related protein expression. Lung. 2002;180(3): 173-179.

200. Lallemand JY, Stoven V, Annereau JP, et al. Induction by antitumoral drugs of proteins that functionally complement CFTR: a novel therapy for cystic fibrosis? Lancet. 1997;350(9079):711-712.

201. Naumann N, Siratska O, Gahr M, Rosen-Wolff A. P-glycoprotein expression increases ATP release in respiratory cystic fibrosis cells. J Cyst Fibros. 2005;4(3):157-168.

202. Ye S, MacEachran DP, Hamilton JW, O'Toole GA, Stanton BA. Chemotoxicity of doxorubicin and surface expression of P-glycoprotein (MDR1) is regulated by the Pseudomonas aeruginosa toxin Cif. Am J Physiol Cell Physiol. 2008;295(3):C807-C818.

203. van der Deen M, Marks H, Willemse BW, et al. Diminished expression of multidrug resistance-associated protein 1 (MRP1) in bronchial epithelium of COPD patients. Virchows Arch. 2006;449(6):682-688.

204. Blokzij1 H, Vander Borght S, Bok LI, et al. Decreased P-glycoprotein (P-gp/MDR1) expression in inflamed human intestinal epithelium is independent of PXR protein levels. Inflamm Bowel Dis. 2007;13(6): 710-720.

205. Henriksson G, Norlander T, Zheng X, Stierna P, Westrin KM. Expression of P-glycoprotein 170 in nasal mucosa may be increased with topical steroids. Am J Rhinol. 1997;11(4):317-321. 
206. Demeule M, Jodoin J, Beaulieu E, Brossard M, Beliveau R. Dexamethasone modulation of multidrug transporters in normal tissues. FEBS Lett. 1999;442(2-3):208-214.

207. Dinis-Oliveira RJ, Duarte JA, Remiao F, Sanchez-Navarro A, Bastos ML, Carvalho F. Single high dose dexamethasone treatment decreases the pathological score and increases the survival rate of paraquat-intoxicated rats. Toxicology. 2006;227(1-2):73-85.

208. Sparreboom A, van Asperen J, Mayer U, et al. Limited oral bioavailability and active epithelial excretion of paclitaxel (Taxol) caused by P-glycoprotein in the intestine. Proc Natl Acad Sci U S A. 1997;94(5):2031-2035

209. Langmann T, Mauerer R, Zahn A, et al. Real-time reverse transcriptionPCR expression profiling of the complete human ATP-binding cassette transporter superfamily in various tissues. Clin Chem. 2003;49(2): 230-238.

210. Kool M, de Haas M, Scheffer GL, et al. Analysis of expression of cMOAT (MRP2), MRP3, MRP4, and MRP5, homologues of the multidrug resistance-associated protein gene (MRP1), in human cancer cell lines. Cancer Res. 1997;57(16):3537-3547.

211. Flens MJ, Zaman GJ, van der Valk $P$, et al. Tissue distribution of the multidrug resistance protein. Am J Pathol. 1996;148(4): 1237-1247.

212. Brechot JM, Hurbain I, Fajac A, Daty N, Bernaudin JF. Different pattern of MRP localization in ciliated and basal cells from human bronchial epithelium. J Histochem Cytochem. 1998;46(4):513-517.

213. van der Deen M, de Vries EG, Visserman H, et al. Cigarette smoke extract affects functional activity of MRP1 in bronchial epithelial cells. J Biochem Mol Toxicol. 2007;21(5):243-251.

214. van der Deen M, Homan S, Timmer-Bosscha H, et al. Effect of COPD treatments on MRP1-mediated transport in bronchial epithelial cells Int J Chron Obstruct Pulmon Dis. 2008;3(3):469-475.

215. Bleasby K, Castle JC, Roberts CJ, et al. Expression profiles of 50 xenobiotic transporter genes in humans and pre-clinical species: a resource for investigations into drug disposition. Xenobiotica. 2006 36(10-11):963-988.

216. Horvath G, Mendes ES, Schmid N, et al. The effect of corticosteroids on the disposal of long-acting beta2-agonists by airway smooth muscle cells. J Allergy Clin Immunol. 2007;120(5):1103-1109.

217. Lips KS, Volk C, Schmitt BM, et al. Polyspecific cation transporters mediate luminal release of acetylcholine from bronchial epithelium. Am J Respir Cell Mol Biol. 2005;33(1):79-88.

218. Horvath G, Schmid N, Fragoso MA, et al. Epithelial organic cation transporters ensure $\mathrm{pH}$-dependent drug absorption in the airway. $\mathrm{Am}$ J Respir Cell Mol Biol. 2007;36(1):53-60.

219. Kummer W, Lips KS, Pfeil U. The epithelial cholinergic system of the airways. Histochem Cell Biol. 2008;130(2):219-234.

220. Kummer W, Wiegand S, Akinci S, et al. Role of acetylcholine and muscarinic receptors in serotonin-induced bronchoconstriction in the mouse. J Mol Neurosci. 2006;30(1-2):67-68.

221. Groneberg DA, Fischer A, Chung KF, Daniel H. Molecular mechanisms of pulmonary peptidomimetic drug and peptide transport. $\mathrm{Am}$ J Respir Cell Mol Biol. 2004;30(3):251-260.

222. Sondergaard HB, Brodin B, Nielsen CU. hPEPT1 is responsible for uptake and transport of Gly-Sar in the human bronchial airway epithelial cell-line Calu-3. Pflugers Arch. 2008;456(3):611-622.

223. Groneberg DA, Eynott PR, Doring F, et al. Distribution and function of the peptide transporter PEPT2 in normal and cystic fibrosis human lung. Thorax. 2002;57(1):55-60.

224. Endter S, Francombe D, Ehrhardt C, Gumbleton M. RT-PCR analysis of ABC, SLC and SLCO drug transporters in human lung epithelial cell models. J Pharm Pharmacol. 2009;61(5):583-591.

225. Saito H, Terada T, Okuda M, Sasaki S, Inui K. Molecular cloning and tissue distribution of rat peptide transporter PEPT2. Biochim Biophys Acta. 1996;1280(2):173-177.

226. Bosquillon C. Drug transporters in the lung - do they play a role in the biopharmaceutics of inhaled drugs? J Pharm Sci. 2010;99(5): 2240-2255.
227. Miyazaki H, Sekine T, Endou H. The multispecific organic anion transporter family: properties and pharmacological significance. Trends Pharmacol Sci. 2004;25(12):654-662.

228. Hagenbuch B, Gui C. Xenobiotic transporters of the human organic anion transporting polypeptides (OATP) family. Xenobiotica. 2008; 38(7-8):778-801.

229. Adachi H, Suzuki T, Abe M, et al. Molecular characterization of human and rat organic anion transporter OATP-D. Am J Physiol Renal Physiol. 2003;285(6):F1188-F1197.

230. Hitzman CJ, Elmquist WF, Wiedmann TS. Development of a respirable, sustained release microcarrier for 5-fluorouracil II: In vitro and in vivo optimization of lipid coated nanoparticles. J Pharm Sci. 2006; 95(5):1127-1143.

231. Hitzman CJ, Elmquist WF, Wattenberg LW, Wiedmann TS. Development of a respirable, sustained release microcarrier for 5-fluorouracil I: In vitro assessment of liposomes, microspheres, and lipid coated nanoparticles. J Pharm Sci. 2006;95(5): 1114-1126.

232. Liang HF, Chen CT, Chen SC, et al. Paclitaxel-loaded poly(gammaglutamic acid)-poly(lactide) nanoparticles as a targeted drug delivery system for the treatment of liver cancer. Biomaterials. 2006;27(9): 2051-2059

233. Musumeci T, Vicari L, Ventura CA, Gulisano M, Pignatello R, Puglisi G. Lyoprotected nanosphere formulations for paclitaxel controlled delivery. J Nanosci Nanotechnol. 2006;6(9-10):3118-3125.

234. Khalid MN, Simard P, Hoarau D, Dragomir A, Leroux JC. Long circulating poly(ethylene glycol)-decorated lipid nanocapsules deliver docetaxel to solid tumors. Pharm Res. 2006;23(4):752-758.

235. Stinchcombe TE. Nanoparticle albumin-bound paclitaxel: a novel Cremphor-EL-free formulation of paclitaxel. Nanomedicine (Lond). 2007;2(4):415-423.

236. Aggarwal AN, Agarwal R. The new ATS/ERS guidelines for assessing the spirometric severity of restrictive lung disease differ from previous standards. Respirology. 2007;12(5):759-762.

237. Kreider ME, Grippi MA. Impact of the new ATS/ERS pulmonary function test interpretation guidelines. Respir Med. 2007;101(11): 2336-2342.

238. Lawson KA, Anderson K, Menchaca M, et al. Novel vitamin E analogue decreases syngeneic mouse mammary tumor burden and reduces lung metastasis. Mol Cancer Ther. 2003;2(5):437-444.

239. Knight V. Anticancer effect of an alpha-TEA liposome aerosol. Exp Biol Med (Maywood). 2005;230(5):291.

240. Knight V, Koshkina NV, Waldrep JC, Giovanella BC, Gilbert BE. Anticancer effect of 9-nitrocamptothecin liposome aerosol on human cancer xenografts in nude mice. Cancer Chemother Pharmacol. 1999; 44(3):177-186.

241. Gagnadoux F, Leblond V, Vecellio L, et al. Gemcitabine aerosol: in vitro antitumor activity and deposition imaging for preclinical safety assessment in baboons. Cancer Chemother Pharmacol. 2006;58(2): 237-244.

242. Gagnadoux F, Le Pape A, Urban T, et al. Safety of pulmonary administration of gemcitabine in rats. J Aerosol Med. 2005;18(2):198-206.

243. Lemarie E, Vecellio L, Hureaux J, et al. Aerosolized gemcitabine in patients with carcinoma of the lung: feasibility and safety study. J Aerosol Med Pulm Drug Deliv. 2011;24(6):261-270.

244. Min R, Li T, Du J, Zhang Y, Guo J, Lu WL. Pulmonary gemcitabine delivery for treating lung cancer: pharmacokinetics and acute lung injury aspects in animals. Can J Physiol Pharmacol. 2008;86(5): 288-298

245. Camus P, Kudoh S, Ebina M. Interstitial lung disease associated with drug therapy. Br J Cancer. 2004;91 Supp1 2:S18-S23.

246. Camus P. Interstitial lung disease in patients with non-small-cell lung cancer: causes, mechanisms and management. Br J Cancer. 2004; 91 Suppl 2:S1-S2.

247. Camus P, Fanton A, Bonniaud P, Camus C, Foucher P. Interstitial lung disease induced by drugs and radiation. Respiration. 2004;71(4): $301-326$. 
248. Merad M, Le Cesne A, Baldeyrou P, Mesurolle B, Le Chevalier T. Docetaxel and interstitial pulmonary injury. Ann Oncol. 1997;8(2): 191-194.

249. Pavlakis N, Bell DR, Millward MJ, Levi JA. Fatal pulmonary toxicity resulting from treatment with gemcitabine. Cancer. 1997;80(2): 286-291.

250. Rabinowits G, Herchenhorn D, Rabinowits M, Weatge D, Torres W. Fatal pulmonary toxicity in a patient treated with gefitinib for nonsmall cell lung cancer after previous hemolytic-uremic syndrome due to gemcitabine. Anticancer Drugs. 2003;14(8):665-668.

251. Suzuki H, Aoshiba K, Yokohori N, Nagai A. Epidermal growth factor receptor tyrosine kinase inhibition augments a murine model of pulmonary fibrosis. Cancer Res. 2003;63(16):5054-5059.

252. Hajos F, Stark B, Hensler S, Prassl R, Mosgoeller W. Inhalable liposomal formulation for vasoactive intestinal peptide. Int J Pharm. 2008;357(1-2):286-294.
253. Pakunlu RI, Wang Y, Tsao W, Pozharov V, Cook TJ, Minko T. Enhancement of the efficacy of chemotherapy for lung cancer by simultaneous suppression of multidrug resistance and antiapoptotic cellular defense: novel multicomponent delivery system. Cancer Res. 2004;64(17):6214-6224.

254. Pakunlu RI, Cook TJ, Minko T. Simultaneous modulation of multidrug resistance and antiapoptotic cellular defense by MDR1 and BCL-2 targeted antisense oligonucleotides enhances the anticancer efficacy of doxorubicin. Pharm Res. 2003;20(3):351-359.

255. Pakunlu RI, Wang Y, Saad M, Khandare JJ, Starovoytov V, Minko T. In vitro and in vivo intracellular liposomal delivery of antisense oligonucleotides and anticancer drug. J Control Release. 2006;114(2): 153-162.

\section{Publish your work in this journal}

The International Journal of Nanomedicine is an international, peerreviewed journal focusing on the application of nanotechnology in diagnostics, therapeutics, and drug delivery systems throughout the biomedical field. This journal is indexed on PubMed Central, MedLine, CAS, SciSearch $\AA$, Current Contents ${ } /$ Clinical Medicine,
Journal Citation Reports/Science Edition, EMBase, Scopus and the Elsevier Bibliographic databases. The manuscript management system is completely online and includes a very quick and fair peer-review system, which is all easy to use. Visit http://www.dovepress.com/ testimonials.php to read real quotes from published authors. 